\title{
Hydrogen permeation through palladium membranes and inhibition by carbon monoxide, carbon dioxide, and steam
}

\section{Citation for published version (APA):}

Boon, J., Pieterse, J. A. Z., van Berkel, F. P. F., van Delft, Y. C., \& van Sint Annaland, M. (2015). Hydrogen permeation through palladium membranes and inhibition by carbon monoxide, carbon dioxide, and steam. Journal of Membrane Science, 496, 344-358. https://doi.org/10.1016/j.memsci.2015.08.061

\section{Document license: \\ TAVERNE}

DOI:

10.1016/j.memsci.2015.08.061

Document status and date:

Published: 15/12/2015

\section{Document Version:}

Publisher's PDF, also known as Version of Record (includes final page, issue and volume numbers)

\section{Please check the document version of this publication:}

- A submitted manuscript is the version of the article upon submission and before peer-review. There can be important differences between the submitted version and the official published version of record. People interested in the research are advised to contact the author for the final version of the publication, or visit the $\mathrm{DOI}$ to the publisher's website.

- The final author version and the galley proof are versions of the publication after peer review.

- The final published version features the final layout of the paper including the volume, issue and page numbers.

Link to publication

\section{General rights}

Copyright and moral rights for the publications made accessible in the public portal are retained by the authors and/or other copyright owners and it is a condition of accessing publications that users recognise and abide by the legal requirements associated with these rights.

- Users may download and print one copy of any publication from the public portal for the purpose of private study or research.

- You may not further distribute the material or use it for any profit-making activity or commercial gain

- You may freely distribute the URL identifying the publication in the public portal.

If the publication is distributed under the terms of Article 25fa of the Dutch Copyright Act, indicated by the "Taverne" license above, please follow below link for the End User Agreement:

www.tue.nl/taverne

Take down policy

If you believe that this document breaches copyright please contact us at:

openaccess@tue.nl

providing details and we will investigate your claim. 


\title{
Hydrogen permeation through palladium membranes and inhibition by carbon monoxide, carbon dioxide, and steam
}

\author{
Jurriaan Boon $^{\mathrm{a}, \mathrm{b}, *}$, J.A.Z. Pieterse ${ }^{\mathrm{a}}$, F.P.F. van Berkel ${ }^{\mathrm{a}}$, Y.C. van Delft ${ }^{\mathrm{a}}$, M. van Sint Annaland ${ }^{\mathrm{b}}$ \\ a Sustainable Process Technology, ECN, P.O. Box 1,1755ZG Petten, The Netherlands \\ ${ }^{\mathrm{b}}$ Chemical Process Intensification, TU/e, P.O. Box 513, 5600MB Eindhoven, The Netherlands
}

\section{A R T I C L E I N F O}

\section{Article history:}

Received 17 April 2015

Received in revised form

27 August 2015

Accepted 29 August 2015

Available online 3 September 2015

Keywords:

Palladium membrane

Hydrogen permeation

Inhibition

Synthesis gas

Constriction resistance

\begin{abstract}
A B S T R A C T
Palladium membranes are being developed for the separation of hydrogen from syngas in industrial applications. However, syngas constituents carbon monoxide, carbon dioxide, and steam are known to adsorb at the membrane surface and inhibit the permeation of hydrogen. The current study combines an experimental study and modelling approach in order to investigate and quantify the inhibition effects. Experiments have been performed with a $2.8 \mu \mathrm{m}$ thick palladium membrane (surface area $174 \mathrm{~cm}^{2}$ ) on a tubular alumina support, including systematic variation of the concentrations of carbon monoxide, carbon dioxide, and steam at 22 bar total pressure and $350-450{ }^{\circ} \mathrm{C}$. Carbon monoxide and steam inhibit hydrogen permeation. No significant effect has been found for carbon dioxide, except indirectly by carbon monoxide produced in situ from carbon dioxide. A constriction resistance model has been derived, explicitly relating the decrease in surface coverage by adsorbed hydrogen to the ensuing decrease in transmembrane flux. Very high surface coverages by inhibiting species $\theta_{i}>0.995$ are predicted. The results highlight that inhibition effects are greatly reduced at high hydrogen partial pressures due to competitive adsorption. Due to the lateral diffusion of permeating hydrogen atoms in the metallic membrane, the thickness of the palladium membrane strongly determines the extent to which surface coverage by non-hydrogen species causes a decrease in hydrogen transmembrane flux. Depending on the operating conditions, membranes are predicted to have an optimal minimum thickness below which an increased intrinsic permeance is offset by an increased impact of inhibition.
\end{abstract}

(c) 2015 Elsevier B.V. All rights reserved.

\section{Introduction}

Palladium has an extremely high solubility for hydrogen atoms and, provided no other species absorb, dense palladium membranes can have an extremely high permselectivity for hydrogen. Therefore, metallic palladium membranes have received a great deal of interest from researchers worldwide since the first discovery of hydrogen permeation in the 19th century [1-4]. Palladium based membranes have been in use for the production of hydrogen in niche markets for decades and membrane separation technologies have significant economic potential in chemical industry, precombustion carbon dioxide capture, and the production of ultrapure hydrogen [1,5-7]. Different companies worldwide commercialise palladium-based membranes for hydrogen production. State of the art membranes consist of a thin $(<50 \mu \mathrm{m})$ metallic palladium or palladium alloy film fixed to a porous metal

\footnotetext{
* Corresponding author at: Sustainable Process Technology, ECN, P.O. Box 1, 1755ZG Petten, The Netherlands.

E-mail address: boon@ecn.nl (J. Boon).
}

or ceramic support [8]. Palladium alloys, rather than pure palladium membranes, are used in processes where $\alpha-\beta$ palladium hydride phase transition may compromise membrane integrity (below the critical point, $T_{\mathrm{c}}=293^{\circ} \mathrm{C}, p_{\mathrm{c}}=20$ bar [9]), to reduce surface poisoning by specific gas phase species, and to further enhance the hydrogen transmembrane flux [4]. Given the state of the art, benchmarking of membranes from different vendors is a crucial step in the introduction of hydrogen membranes to demonstrate the maturity and performance under industrially relevant conditions, i.e. about $50 \mathrm{vol} \%$ hydrogen at 30 bar total pressure and $400{ }^{\circ} \mathrm{C}$ (see discussion below). In previous papers $[8,10]$, a strategy has been introduced consisting of systematic experiments and model development for the description of hydrogen permeation at high partial pressure (11-15 bar) and temperature $\left(350-450^{\circ} \mathrm{C}\right)$. For hydrogen-nitrogen mixtures with and without sweep, it was found that the main resistances to mass transfer are concentration polarisation in the retentate, hydrogen permeation through the metallic palladium layer, and (particularly in cases where sweep gas is used) a diffusional resistance in the support layer. The model derived has been shown to quantify, as a 
function of operating conditions, the intrinsic and external mass transfer resistances. In this paper this work is extended with dedicated experiments as well as model development to account for inhibition effects by syngas species carbon monoxide, carbon dioxide, and steam.

The term inhibition refers to the observed decrease in transmembrane flux due to the competitive adsorption of gaseous species on the membrane surface. As such, it is fundamentally different from mass transfer resistances (e.g., concentration polarisation) and depletion. For palladium based membranes, inhibition by carbon monoxide, carbon dioxide, and steam has been reported at temperatures around $400{ }^{\circ} \mathrm{C}$ [11-20]. Barbieri et al. [21] interpreted the observed decrease in hydrogen flux through a palladium-silver membrane at $319-450{ }^{\circ} \mathrm{C}$ with inhibition by up to 2 bar carbon monoxide in terms of a Sieverts-Langmuir model, assuming a linear correlation between the decrease in hydrogen permeance and the surface coverage by carbon monoxide. Consequently, they accounted for the membrane surface fraction not available for hydrogen permeation using a Langmuir affinity constant for carbon monoxide and a temperature dependent 'permeance reduction factor'. Mejdell et al. [22] confirmed the model for palladium-silver at $275-350^{\circ} \mathrm{C}$ and $0-0.15$ bar carbon monoxide, while measuring a weak effect for carbon dioxide at $350{ }^{\circ} \mathrm{C}$. Inhibition by carbon monoxide and carbon dioxide for a palladium membrane $\left(350-450{ }^{\circ} \mathrm{C}\right.$ ) could be described by a similar relation by Augustine et al. [16]. Building on these Langmuir isotherm based inhibition models, Israni and Harold [23] adopted a more comprehensive approach and derived a competitive adsorption model for the inhibition by methanol, steam, carbon dioxide, and carbon monoxide on the hydrogen flux through a palladium-silver membrane at $225-300{ }^{\circ} \mathrm{C}$ and pressures of 3-5 bar. Recently, Patrascu and Sheintuch [20] applied this inhibition model to a pure palladium membrane in a membrane reformer, but found significantly stronger inhibition by carbon monoxide. Abir and Sheintuch [24] developed a first principles model of adsorption, subsurface penetration, and atomic hydrogen diffusion and found that inhibition by propylene and carbon monoxide substantially reduced the hydrogen surface coverage. While these previous studies have provided better insight into the phenomenon of inhibition, they are limited in several important respects. Firstly, in terms of operating conditions, inhibition has not yet been studied in industrial syngas mixtures with systematic variations of the concentrations of hydrogen, carbon monoxide, carbon dioxide, and steam at relevant temperatures and pressures. Secondly, up until now the modelling approach has been based on a reduced, onedimensional model for the diffusion of hydrogen atoms across the metal membrane.

A comprehensive model of hydrogen permeation under inhibition would require a proper description of the mass transfer resistance in the membrane module, of the resistance in the membrane support, and of the permeation across the metal membrane layer, i.e. accounting for lateral diffusion in the metal. Mass transfer resistance in the membrane module becomes increasingly important with increasing transmembrane flux and it has been widely discussed in the literature $[10,12,25,26]$. Peters et al. [25] present a clear and comprehensive discussion of the effects of dilution, depletion, and concentration polarisation, all lowering the partial pressure of hydrogen at the membrane surface on the feed/retentate side. The same effects, mutatis mutandis, arise at the sweep/permeate side of the membrane. In addition, the membrane support can add friction as well as a diffusional resistance to the mass transfer resistance [10]. Kinetic modelling has shown that at industrially relevant temperatures above $300{ }^{\circ} \mathrm{C}$ and high hydrogen partial pressures, the diffusion of hydrogen atoms across the metal membrane is the rate limiting step in the absence of inhibition $[27,28]$. At least for membranes with a thickness of $1 \mu \mathrm{m}$ and over, a deviation of the pressure exponent in the flux equation from $1 / 2$ (Sieverts' law) in these conditions is related to the hydrogen solubility in the palladium bulk rather than due to surface limitations. With inhibiting species in the feed gas, the number of sites occupied by hydrogen atoms will decline and surface limitations become important, changing the rate limiting step. Indeed, kinetic modelling has shown that the rate of hydrogen dissociative adsorption becomes important at high coverage by carbon monoxide [15]. However, a study of the rate of adsorption and permeation of hydrogen, combined with the rates of adsorption and desorption of inhibiting syngas species, is lacking.

In the Dutch national programme CATO2, palladium-based membranes have been benchmarked for pre-combustion carbon dioxide capture in natural gas fuelled combined cycle power plants and in refineries [8,29]. Within this framework, a model is developed to describe the permeation of hydrogen in industrially relevant conditions, including the presence of inhibiting species. A systematic approach is adopted, first developing models that describe mass transfer resistance in the module and membrane support [10], then continuing to describe the kinetics of adsorption and desorption of hydrogen and the decrease in the apparent permeance by inhibiting species, and to account for diffusion of hydrogen atoms in case of inhibition. This study not only aims at further clarifying the nature of the inhibition phenomenon, but also to allow for the interpretation of membrane performance measurements in industrial syngas applications.

This paper first discusses the results of a dedicated set of experiments done with a supported palladium membrane, systematically varying the concentrations of syngas species carbon monoxide, carbon dioxide, and steam. While palladium alloys may arguably be considered state of the art, the current work benefits from having a pure palladium membrane. Apart from the fact that the operating conditions are well above the critical temperature and phase separation is impossible, the description of the adsorption and diffusion of hydrogen across pure palladium is more straightforward. Subsequently, a set of models is developed that is required for interpretation of the experiments. Firstly, the membrane flux equation is derived from pure hydrogen experiments and validated with hydrogen-nitrogen separation experiments. Secondly, a novel set of model equations is derived that describes the response of dissociative hydrogen adsorption and permeation rates to the surface coverage by inhibiting species based on the concept of constriction resistance. Finally, the complete set of models is used to quantify the observed decline in permeance in the presence of syngas species.

\section{Material and methods}

\subsection{Experiment}

Experiments have been performed on ECN's 'Process Development Unit' (PDU), described in more detail elsewhere [14,30,31]. The experimental procedure has been described previously by Boon et al. $[8,10]$.

A supported palladium membrane was obtained from Hysep (The Netherlands) [32]. It consists of a $2.8 \mu \mathrm{m}$ thick layer of palladium on a ceramic support tube. The support is a porous alumina tube of $14 \mathrm{~mm}$ outer diameter and $2 \mathrm{~mm}$ thickness and contains three layers of different characteristics [10]. After sealing, the effective length of the membrane is $0.396 \mathrm{~m}$, and the surface area $174 \mathrm{~cm}^{2}$. The membrane tube was mounted in a cylindrically shaped module (26.62 mm internal diameter), containing an insert tube ( $6 \mathrm{~mm}$ outer diameter) intended for sweep gas, creating a double annulus geometry enclosing the membrane. 
Table 1

Experimental conditions.

\begin{tabular}{|c|c|c|c|c|c|c|c|c|}
\hline Series & Retentate pressure bar (a) & Permeate pressure bar (a) & Pressure difference bar & $y_{\mathrm{H}_{2}, \mathrm{f}}$ & $y_{\mathrm{N}_{2}, \mathrm{f}}$ & $y_{\mathrm{CO}, \mathrm{f}}$ & $y_{\mathrm{CO}_{2}, \mathrm{f}}$ & $y_{\mathrm{H}_{20}, \mathrm{f}}$ \\
\hline Pure $\mathrm{H}_{2}$ & $2.1-31$ & $1.0-30$ & $1.0-6.0$ & 1 & & & & \\
\hline $\mathrm{H}_{2}-\mathrm{N}_{2}$ & 22 & 2.0 & 20 & $0.50-0.70$ & $0.30-0.50$ & & & \\
\hline Syngas & 22 & 2.0 & 20 & $0.50-0.70$ & $0.04-0.40$ & $0-0.02$ & $0-0.15$ & $0-0.29$ \\
\hline
\end{tabular}

The current data were measured in a dedicated set of experiments, aiming at studying the inhibition effect. Measurements were performed at conditions as close as possible to envisaged industrial processes, e.g. pre-combustion decarbonisation in a power plant operation for which natural gas is converted by autothermal reforming and pre-shifted upstream the membrane separator unit [8]. Consequently, the measurements were done with $p_{\mathrm{H}_{2}}=11-15$ bar, i.e. closer to industrial conditions and higher than reported so far in the literature. Three series of measurements were done, summarised in Table 1: pure hydrogen measurements, hydrogen-nitrogen separation experiments, and finally a series of experiments with systematic addition of carbon monoxide, carbon dioxide, and steam to the feed. No sweep gas was used in any of the measurements.

The membrane was first subjected to a stabilisation programme in pure hydrogen (2.1/1.1 bar). Then, the experiments were performed (Table 1), where the syngas data were measured over a period of 20 days. Process values have been recorded at twenty minute intervals between varying conditions and the measurements have been repeated three times at ten minute intervals, so each condition was typically sustained for thirty minutes. The intervals were extended if necessary until the pressures $( \pm 5 \mathrm{kPa})$

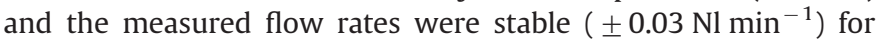
five minutes. The hydrogen mass balances were mostly within $\pm 5 \%$. Incidental measurements with a mass balance error more than $\pm 10 \%$ were discarded. Over the test period, traces of up to $1.9 \mathrm{vol} \%$ of nitrogen, $0.2 \mathrm{vol} \%$ of carbon dioxide, and $0.02 \mathrm{vol} \%$ of carbon monoxide were measured in the permeate, indicating that the apparent permselectivity, based on linearised permeance, has been in the range of 120 . While this is a relatively low value for a palladium membrane, only small amounts of non-hydrogen species appear in the permeate so the permselectivity is still sufficiently high not to have a significant effect on the interpretation of the experimental results below.

In total, the membrane was tested for $780 \mathrm{~h}$ on stream, and recurring standard measurements were performed in order to verify membrane stability (pure hydrogen, $400^{\circ} \mathrm{C}, p_{\mathrm{H}_{2} \text {, ret }}=2.1 \mathrm{bar}$, $p_{\mathrm{H}_{2} \text {,perm }}=1.1 \mathrm{bar}$ ). The 105 inhibition experiments were randomised in order to prevent confounding experimental variations and measurement time, with the notable exception of experiments with carbon monoxide alone. Because it was expected that this particular set of conditions might compromise membrane stability, the twenty hydrogen/carbon monoxide/nitrogen separation tests were performed at the end of the experimental programme (662-722 h). The inhibition experiments were measured at a hydrogen recovery of up to $70 \%$.

\subsection{Modelling}

The systematic approach in experiments was mirrored by model development. The inhibition parameters were determined from the measured fluxes in a staged approach, shown in Fig. 1, briefly outlined here first and discussed in more detail in the following sections.

- For all experimental measurements, the driving force along the membrane was determined using a membrane module model

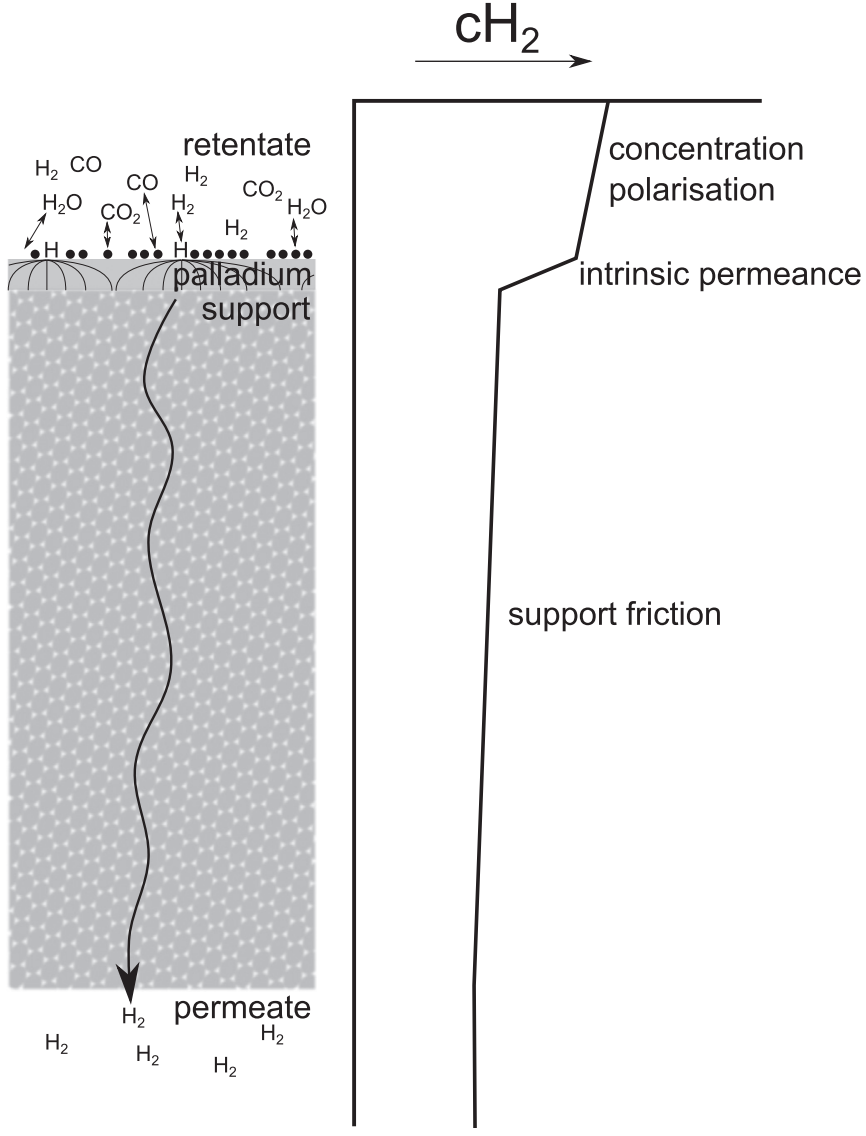

Fig. 1. Schematic representation of the transport resistances accounted for in the current model.

(Section 2.2.1), including an explicit relation for the pressure drop in the membrane support (Eq. (6)). In this manner, depletion of hydrogen and mass transfer resistances accounted for and the actual driving force for permeation across the palladium membrane layer is calculated.

- Pure hydrogen experiments were used to fit the coefficients in the flux equation (Eq. (22)) for the palladium membrane.

- For all measurements with carbon monoxide, carbon dioxide, or steam, the module model was used to fit $\langle\eta\rangle$, which is defined as the average value along the membrane length of the actual measured flux divided by the flux as predicted by the flux equation, which would have been measured in the absence of inhibition. This is necessary because inhibition lowers the transmembrane flux and thereby lowers the effect of concentration polarisation.

- The values of $\langle\eta\rangle$ found for the inhibition data were used to relate the decline in flux to the reduction in the fraction of the surface covered by adsorbed hydrogen atoms $\left(\theta_{\mathrm{H}}\right)$ through the constriction resistance model (Eq. (43)).

- The derived kinetic relations for adsorption and desorption of hydrogen were used to calculate the fraction of the surface uncovered $(1-\theta)$ from $\theta_{\mathrm{H}}$ for the inhibition data, accounting for the splitting of molecular hydrogen into $\mathrm{H}$ atoms. 
- From $\theta_{\mathrm{H}}$, the rate of hydrogen desorption is calculated. From the transmembrane flux and the rate of desorption, the rate of adsorption can be calculated from a mass balance for hydrogen (Eq. (34)). The rate of adsorption allows determining the value of $(1-\theta)$ from adsorption kinetics.

- Finally, the experiments with a single inhibitive species and subsequently the complete dataset were used to fit the coefficients in the relation for $\langle\eta\rangle$ versus the average partial pressures of carbon monoxide, carbon dioxide, and steam.

\subsubsection{Module model}

Previously, a two-dimensional module model has been introduced and used for the modelling of mass transfer resistance in the membrane module $[10,26]$. The two-dimensional model has been used here to validate a computationally fast, one-dimensional module model that allows for regression of the local reduction in the transmembrane flux, given the measured outlet hydrogen concentration in the retentate.

On the feed/retentate side, concentration polarisation needs to be accounted for. The driving force for hydrogen permeation can only be evaluated from the hydrogen concentration at the membrane surface, $y_{\mathrm{H}_{2}, m}$. This is done iteratively, using a model that expresses the flux of hydrogen towards the membrane as a function of the average concentration in the retentate and the surface concentration at the membrane surface. The flux of hydrogen towards the membrane in steady state, with a developed velocity and concentration profile, is given by [33]

$N_{\mathrm{H}_{2}, \mathrm{r}}=-\frac{p}{R T} \frac{D}{r_{\mathrm{m}} \ln \left(\frac{r_{\mathrm{o}}}{r_{\mathrm{m}}}\right)} \ln \left(\frac{1-y_{\mathrm{H}_{2}, o}}{1-y_{\mathrm{H}_{2}, m}}\right)$

which can also be approximated in terms of the dimensionless Sh number and the mixing cup average hydrogen concentration $\left\langle\mathrm{C}_{\mathrm{H}_{2}}\right\rangle$ [26,34,35]:

$N_{\mathrm{H}_{2}, \mathrm{r}}=-\frac{p}{R T} \frac{\operatorname{Sh} D}{d_{\mathrm{h}}} \frac{\left\langle y_{\mathrm{H}_{2}}\right\rangle-y_{\mathrm{H}_{2}, \mathrm{i}}}{1+\left(\left\langle y_{\mathrm{H}_{2}}\right\rangle+y_{\mathrm{H}_{2}, \mathrm{i}}\right) / 2}$

Sh $\equiv \frac{k d_{\mathrm{h}}}{D}$

For cases with developed velocity profile and developing concentration profile, i.e. including an entrance effect for the concentration, the value of Sh can be correlated as a function of the $\mathrm{Gz}$ number, approaching a constant value of 6.18 further downstream from the inlet [26]:

$\mathrm{Sh}= \begin{cases}1.07 \mathrm{Gz}^{0.42} & \mathrm{Gz}>62 \\ 6.18 & \mathrm{Gz} \leq 62\end{cases}$

$\mathrm{Gz}=\operatorname{Re} \mathrm{Sc} \frac{d_{\mathrm{h}}}{z}$

All measurements presented here have been performed without sweep gas. Therefore, there is no mass transfer resistance on the permeate side. There is also no gas-gas diffusion resistance in the porous membrane support. Only a small pressure drop in the support on the permeate side is accounted for [10]:

$\frac{d p}{d r}=\frac{r_{\mathrm{m}} N_{\mathrm{m}}}{r \bigoplus_{\mathrm{H}, \mathrm{M}}^{\mathrm{e}}}\left[-\frac{1}{R T}\left(1+\frac{B_{0} p}{\mu \bigoplus_{\mathrm{H}, \mathrm{M}}^{\mathrm{e}}}\right)\right]^{-1}$

Depletion along the axial coordinate is modelled by integrating $\frac{d F_{\mathrm{H}_{2}}}{d z}=-\pi d_{\mathrm{m}} N_{\mathrm{m}, \mathrm{H}_{2}}$ from the inlet specification over the length of the membrane using ode45 in Matlab 2014b.

\subsubsection{Hydrogen permeation}

Ward and Dao [27] have built a kinetic model for the permeation of hydrogen across a palladium membrane, which was further elaborated by Deveau et al. [28]. They have shown that under relevant conditions, the diffusion of hydrogen atoms across the palladium metal membrane is the rate limiting step in the absence of inhibition, which is to be confirmed for the conditions in the current work. Their fundamental assumption, however, is that the diffusion equation for hydrogen atoms across the metal palladium can be reduced to a one-dimensional ordinary differential equation.

The ideal steady-state diffusion of hydrogen in palladium is governed by Laplace's equation and Fick's first law:

$0=\nabla^{2} c_{\mathrm{H}}$

$N_{\mathrm{H}}=-D_{\mathrm{H}} \nabla c_{\mathrm{H}}$

$D_{\mathrm{H}}$ may be taken as an average constant during steady-state permeation, omitting the correction for nonideality, provided that the nonideality (value of $n$ ) is properly accounted for in the boundary conditions [36].

In this work, we argue that the one-dimensional description of the diffusion process is strictly valid only for a pure hydrogen gas phase, i.e. in the absence of inhibition. Instead, as indicated in Fig. 2, a two-dimensional cylindrical model is proposed. The lines in Fig. 2c represent the diffusion path of a hydrogen atom from an adsorbed state at the feed side to the permeate side. Eq. (8) is written in cylindrical coordinates:

$0=\frac{1}{r} \frac{\partial}{\partial r}\left(r \frac{\partial c_{\mathrm{H}}}{\partial r}\right)+\frac{\partial^{2} c_{\mathrm{H}}}{\partial z^{2}}$

The boundary conditions are related to the defined geometry. The surface of the membrane consists of $N_{\mathrm{Pd}}$ palladium atoms that may be considered adsorption sites, of which $\left(\theta_{\mathrm{H}} N_{\mathrm{Pd}}\right)$ are occupied by a hydrogen atom. Although some sort of order may be present in the distribution of adsorbed hydrogen atoms on the surface, as discussed above, this will be hampered by coadsorbed species in syngas. Hence, a permeation model is proposed here that is based on the average distance between adsorbed hydrogen atoms. If the average distance between two adsorbed hydrogen atoms is $2 \rho_{\mathrm{H}}$, then $\rho_{\mathrm{H}}$ is the radius of the cylindrical model. The surface area of an adsorbed hydrogen atom is given by the concentration of hydrogen occupied palladium atoms

$N_{\text {Pd }}=\left(N_{A} C_{\text {Pd }}\right)^{2 / 3}$

$r_{\mathrm{H}}=\sqrt{\frac{1}{\pi \theta_{\mathrm{H}} N_{\mathrm{Pd}}}}$

with (accounting for steam dissociation, see Table 2)

$\theta_{\mathrm{H}}=\theta_{\mathrm{H}_{2}}+\frac{2}{3} \theta_{\mathrm{H}_{2} \mathrm{O}}$

The flux of atomic hydrogen is given by

$\vec{N}_{\mathrm{H}}=\left[\begin{array}{c}-\frac{D_{\mathrm{H}}}{r} \frac{\partial c_{\mathrm{H}}}{\partial r} \\ -D_{\mathrm{H}} \frac{\partial c_{\mathrm{H}}}{\partial z}\end{array}\right]$

Many studies have been published on the diffusivity of hydrogen atoms in metallic palladium, and the review by Völkl and Alefeld 


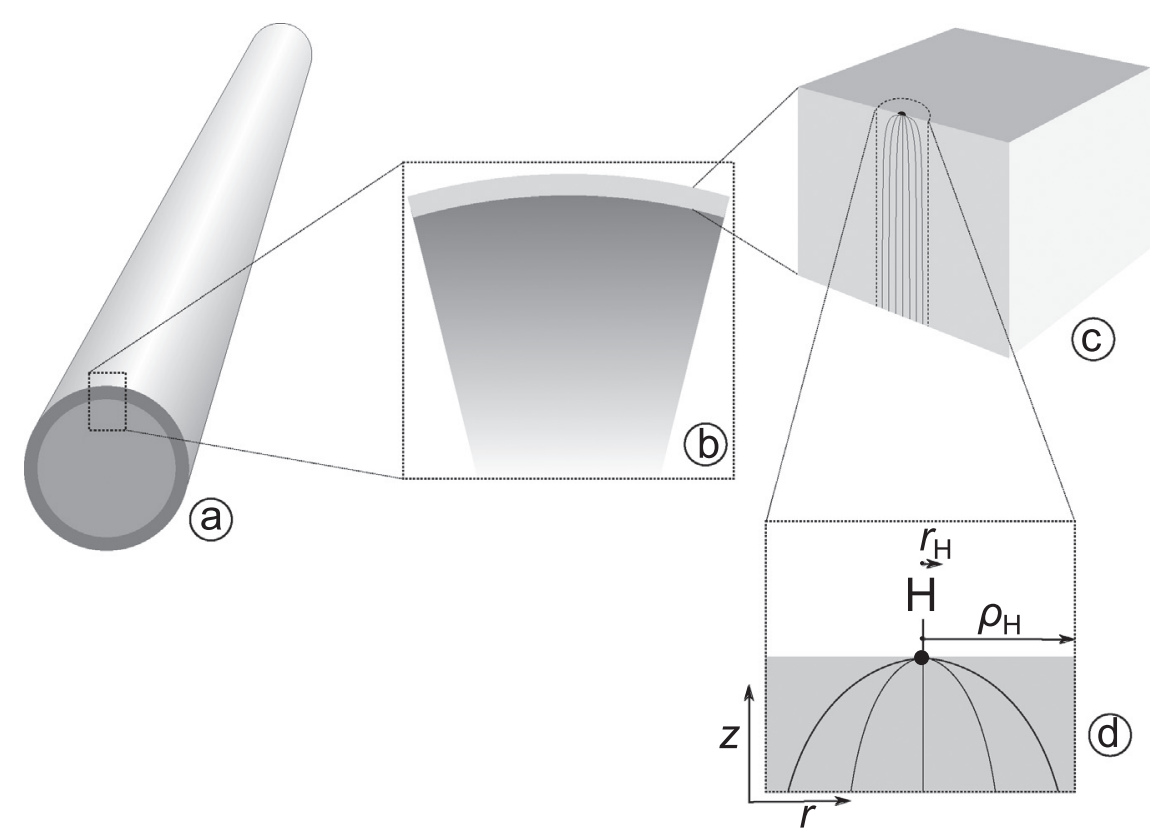

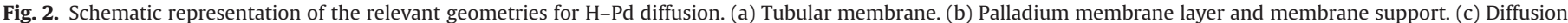
of $\mathrm{H}$ atoms across the metallic palladium layer. (d) Cylindrical geometry of the diffusion model defining $r_{\mathrm{H}}$ and $\rho_{\mathrm{H}}$.

Table 2

Adsorption equilibrium reaction equations, * represents an adsorption site.

\begin{tabular}{llll}
\hline $\mathrm{H}_{2}+2^{*}$ & $\rightleftharpoons$ & $2^{*}-\mathrm{H}$ & $\mathrm{A}$ \\
$\mathrm{H}_{2} \mathrm{O}+3^{*}$ & $\rightleftharpoons$ & $2 *-\mathrm{H}+{ }^{*}-\mathrm{O}$ & $\mathrm{B}$ \\
$\mathrm{CO}^{*}$ & $\rightleftharpoons$ & $*-\mathrm{CO}$ & $\mathrm{C}$ \\
$\mathrm{CO}_{2}+2^{*}$ & $\rightleftharpoons$ & $*-\mathrm{CO}+{ }^{*}-\mathrm{O}$ & $\mathrm{D}$ \\
\hline
\end{tabular}

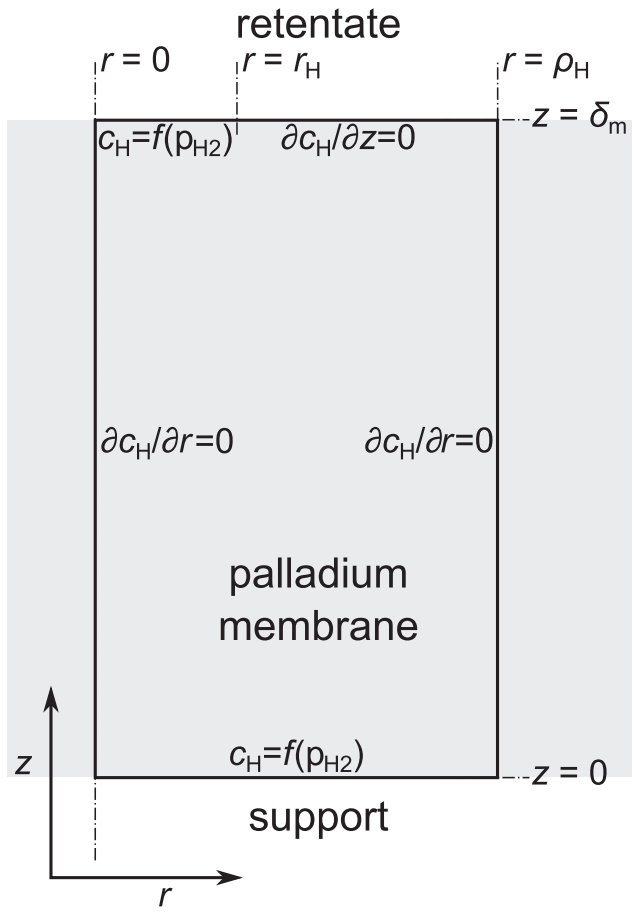

Fig. 3. Two-dimensional axisymmetrical model geometry and boundaries for H-Pd diffusion, not drawn to scale.
[37] summarises them in an Arrhenius relation corresponding to

$$
D_{\mathrm{H}}=D_{\mathrm{H}, 0} \exp \left(\frac{-E_{D}}{R T}\right)
$$

with $D_{0}=2.9 \cdot 10^{-7} \mathrm{~m}^{2} \mathrm{~s}^{-1}$ and $E_{D}=22.2 \mathrm{~kJ} \mathrm{~mol}^{-1}$. The corresponding boundary conditions are (Fig. 3 )

$\frac{\partial c_{\mathrm{H}}}{\partial r}=0, \quad r=\left\{0, \rho_{\mathrm{H}}\right\}, \quad 0 \leq z \leq \delta_{\mathrm{m}}$

$\frac{\partial c_{\mathrm{H}}}{\partial z}=0, \quad r_{\mathrm{H}} \leq r \leq \rho_{\mathrm{H}}, \quad z=\delta_{\mathrm{m}}$

$c_{\mathrm{H}}=K_{0} \exp \left(\frac{E_{\mathrm{k}}}{R T}\right) p_{\mathrm{H}_{2}, \mathrm{r}}^{n}, \quad 0 \leq r \leq r_{\mathrm{H}}, \quad z=\delta_{\mathrm{m}}$

$c_{\mathrm{H}}=K_{0} \exp \left(\frac{E_{\mathrm{k}}}{R T}\right) p_{\mathrm{H}_{2}, \mathrm{p}}^{n}, \quad 0 \leq r \leq \rho_{\mathrm{H}}, \quad z=0$

For full coverage, $r_{\mathrm{H}}\left(\theta_{\mathrm{H}}=1\right)=0.14 \mathrm{~nm}$, in line with the covalent atomic radius of a palladium atom of $1.3 \pm 0.1 \AA$ [38]. Thereby, for higher coverages, Eq. (9) reduces to the standard one-dimensional diffusion model

$N_{\mathrm{H}}=-D_{\mathrm{H}} \frac{\partial c_{\mathrm{H}}}{\partial z}$

$N_{\mathrm{H}}=-D_{\mathrm{H}} \frac{c_{\mathrm{H}, \mathrm{r}}-c_{\mathrm{H}, \mathrm{p}}}{\delta_{\mathrm{m}}}$

$N_{\mathrm{H}}=-Q\left(p_{\mathrm{H}_{2, \mathrm{r}}}^{n}-p_{\mathrm{H}_{2, \mathrm{p}}}^{n}\right)$

with

$Q=Q_{0} \exp \left(\frac{-E_{Q}}{R T}\right)$ 

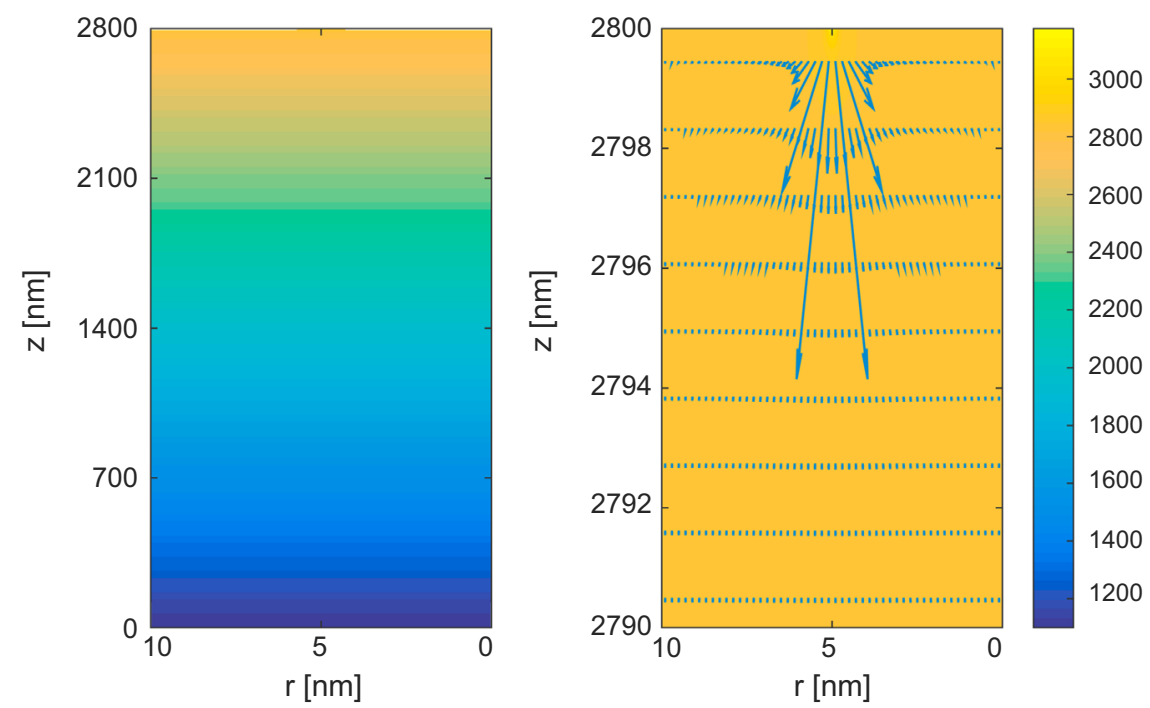

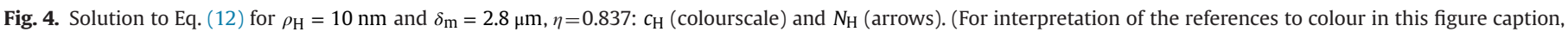
the reader is referred to the web version of this paper.)

$Q=K_{0} \exp \left(\frac{E_{\mathrm{k}}}{R T}\right) \frac{D_{0}}{\delta_{\mathrm{m}}} \exp \left(\frac{-E_{D}}{k_{B} T}\right)$

However, for $\theta_{\mathrm{H}}$ significantly lower than 1, e.g. because of inhibition, the model will allow to account for the increase in length of the diffusion path for hydrogen atoms across the palladium layer (Fig. 2), which is commonly known as constriction resistance in analogous problems in mechanical and electrical engineering [3942 ]. It is a geometric consideration that accounts for the fact that, because of the surface structure, only part of the surface is accessible for contact friction, for electric current, or in the present system for hydrogen permeation. For the latter, the constriction resistance model accounts for the lateral diffusion of hydrogen atoms when permeating from a retentate surface that has been largely covered by inhibiting species. The lateral diffusion causes hydrogen atoms to effectively fan out while crossing the palladium membrane, thereby reducing the impact of surface inhibition on the transmembrane flux. The two-dimensional permeation model aims to quantify the decrease in the rate of hydrogen transmembrane permeation for a given equilibrium with the gas phase on either side and as a function of the amount of surface that is blocked by adsorption of inhibiting species.

The model has been solved in Comsol Multiphysics 4.3b (transport of diluted species, $10^{6}-10^{7}$ elements). A typical simulation result is shown in Fig. 4.

The developed constriction resistance model is based on a continuum approach for the description of the diffusion path of an adsorbed hydrogen atom across the metallic palladium membrane. The ability of adsorbed hydrogen atoms to move laterally over the membrane surface is ignored, as is the renewal of the adsorbed species on the surface. However, the palladium surface in the current system consists of $3 \cdot 10^{17}$ exposed palladium atoms and the hypothesis underlying the current study is that statistically averaged, the continuum approach holds.

\subsubsection{Surface adsorption of hydrogen and other syngas constituents}

Ideally, the relation between $\left\langle\theta_{\mathrm{CO}}\right\rangle,\left\langle\theta_{\mathrm{CO}_{2}}\right\rangle$, and $\left\langle\theta_{\mathrm{H}_{2} \mathrm{O}}\right\rangle$ is expressed as a function of the partial pressures of the respective components, i.e. in terms of an adsorption isotherm [15,20-23]. The kinetic theory of gases predicts the rate of adsorption of species from the gas phase as the product of the rate of collision, according to the Hertz-Knudsen formula, and the sticking coefficient $s$ [43]:

$r_{\mathrm{a}, i}=\frac{p_{i} s_{i}}{\sqrt{2 \pi m_{i} k_{B} T}}$

The sticking coefficient quantifies the probability of an impinging molecule to become adsorbed on a surface instead of being scattered back into the gas phase and, correspondingly, equals the rate of adsorption divided by the rate of bombardment. The equation for the sticking coefficient depends on the order adsorption and thereby determines the exponent in the extended Langmuir equation introduced below.

For hydrogen, the sticking coefficient on a palladium surface has been extensively studied. As discussed by Ward and Dao [27], the dissociative adsorption can be modelled with a quasi-chemical approach, based on the assumptions that the adsorption is not activated, the adsorbed hydrogen atoms are structured because of adatom-adatom interaction, and molecules from a physisorbed precursor state migrate across the surface towards a pair of empty sites [44]:

$s_{\mathrm{H}}(\theta)=\frac{s_{\mathrm{H}, 0}}{1+K_{\mathrm{H}}\left(1 / \theta_{00}-1\right)}$

$\theta_{00}=1-\theta-\frac{2 \theta(1-\theta)}{1+\sqrt{1-4 \theta(1-\theta)\left(1-\exp \left(-w / k_{B} T\right)\right)}}$

This approach is justified for pure hydrogen, where the surface coverage of hydrogen atoms is fairly high. In case the surface coverage is low, as with a system under significant inhibition, the adatom-adatom interaction for hydrogen will be severely hampered [45]. It is therefore assumed that in case of inhibition Langmuir kinetics is a more appropriate approach and for dissociative adsorption:

$S_{\mathrm{H}}(\theta)=S_{\mathrm{H}, 0}(1-\theta)^{2}$

The initial sticking coefficient for hydrogen on palladium is assumed to be unity [27]. Similar to the adsorption of hydrogen, the adsorption of inhibiting species is modelled with Langmuir kinetics accounting for dissociation. Different accounts for steam adsorption exist in the literature. Except at very low temperatures, steam is reported to adsorb dissociatively to form adsorbed 
hydroxyl, atomic oxygen and atomic hydrogen atoms [46-48]. Engel and Kuipers [49] and Nyberg and Tengstål [50] found no significant amounts of hydroxyl groups on the palladium surface and that the formation of hydroxyl groups from adsorbed oxygen and hydrogen atoms is the rate limiting step in the formation of water at temperatures above $300 \mathrm{~K}$. In contrast, computational studies suggest non-dissociative adsorption based on the high activation energy of dissociation [24]. For the current conditions, steam is assumed to adsorb dissociatively into atomic oxygen and hydrogen, but this assumption is of little consequence for the analysis below. Carbon monoxide adsorbs molecularly [51-54]. Supported palladium at temperatures above $240{ }^{\circ} \mathrm{C}$ has been shown to dissociate carbon dioxide and hence becomes active for catalysing the reverse water-gas shift reaction and carbon dioxide reforming of methane [55-57]. Thus, carbon dioxide will adsorb dissociatively into carbon monoxide and atomic oxygen. The adsorption equilibrium relations on which the kinetic models are based are summarised in Table 2. Note that surface impurities may play an important role in the adsorption on the palladium surface, which is not addressed in the current study.

The adsorption and desorption reactions inevitably lead to heterogeneously catalysed chemical conversions as well. Because carbon monoxide is found when carbon dioxide is fed and vice versa, carbon monoxide and carbon dioxide are evidently interconverted via water-gas shift (WGS) and reverse water-gas shift (RWGS) reactions [55]

$\mathrm{CO}+\mathrm{H}_{2} \mathrm{O} \rightleftharpoons \mathrm{CO}_{2}+\mathrm{H}_{2}$

which has also been reported to occur over steel module parts $[13,58]$. Up to $1.9 \mathrm{~mol} \%$ of methane is measured in the retentate when either carbon monoxide or carbon dioxide is fed, which is evidence of palladium-catalysed methanation $[59,60]$

$\mathrm{CO}+3 \mathrm{H}_{2} \rightleftharpoons \mathrm{CH}_{4}+\mathrm{H}_{2} \mathrm{O}$

$\mathrm{CO}_{2}+4 \mathrm{H}_{2} \rightleftharpoons \mathrm{CH}_{4}+2 \mathrm{H}_{2} \mathrm{O}$

The mechanism of these reactions is still subject of considerable debate and the current experimental conditions are rather atypical, particularly because of the important role of the catalyst support in heterogeneous catalysis $[59,61,60]$. Importantly, methane is not necessarily produced from surface carbon (cf. [57]), but it can be produced from adsorbed carbon monoxide, and possibly carbon dioxide. Since there is no sign of progressive coking, i.e. no decline in transmembrane hydrogen flux as discussed below, and because of the high partial pressure of hydrogen (11-15 bar), the surface coverage by carbon is neglected: $\theta_{\mathrm{C}} \approx 0$, which is in line with observations by Erdöhelyi et al. [57].

Adsorption is naturally accompanied by desorption. The rate of desorption depends on the order $n$, activation energy $E_{\mathrm{d}}$, and a desorption constant $[28,43]$ :

$r_{\mathrm{d}, i}=k_{\mathrm{d}, i} \theta_{i}^{n_{i}} \exp \left(\frac{E_{\mathrm{d}}}{R T}\right)$

For hydrogen, again in the absence of inhibitive species and high surface coverage, Ward and Dao [27] propose a more elaborate equation accounting for interaction of adsorbed hydrogen:

$r_{\mathrm{d}, \mathrm{H}_{2}}=2 k_{\mathrm{d}, i} \theta_{\mathrm{H}} N_{\mathrm{Pd}}^{2} \exp \left(\frac{-2 E_{\mathrm{d}, i}}{R T}\right)\left(1-\frac{2-2 \theta_{\mathrm{H}}}{1+\sqrt{1-4 \theta_{\mathrm{H}}\left(1-\theta_{\mathrm{H}}\right)\left(1-\exp \left(\frac{-w}{k_{B} T}\right)\right)}}\right)$

In steady state, the membrane flux and the rates of adsorption and desorption are coupled via a simple mass balance:
$N_{\mathrm{m}, i}=r_{\mathrm{a}, i}-r_{\mathrm{d}, i}$

For non-permeating species $\left(i \neq \mathrm{H}_{2}\right)$, the rates of adsorption and desorption are necessarily equal, leading to a multicomponent extended Langmuir adsorption isotherm [43]. The set of equations derived above then leads to an extended Langmuir equation, using Eq. (32),

$\theta_{i}=\frac{\left(b_{i} p_{i}\right)^{1 / n_{i}}}{1+\sum_{i}\left(b_{i} p_{i}\right)^{1 / n_{i}}}$

$b_{i}=b_{i, 0} \exp \left(\frac{-E_{\mathrm{a}, i}}{R T}\right)$

and $n_{i}$ is defined in accordance with the molecular or dissociative mechanisms summarised in Table 2. When $N_{\mathrm{m}, \mathrm{H}_{2}} \ll r_{\mathrm{a}, \mathrm{H}_{2}} \simeq r_{\mathrm{d}, \mathrm{H}_{2}}$, which is the case without inhibition under the current conditions, adsorption equilibrium exists for hydrogen as well, based on Eq. (33). Note that the adsorption model derived here is consistent with the model that Israni and Harold [23] derived for inhibition in methanol steam reforming with a palladium-silver membrane. The values for $n_{i}$ are different however, since the temperature range is different and dissociative adsorption needs to be accounted for in the current model.

In case of inhibition, a significant decline in transmembrane flux is measured. Below, it will be shown that a significant reduction in flux in the current conditions implies a very high surface coverage by inhibiting species, which in turn invalidates the assumption of adsorption-desorption equilibrium for hydrogen made above, i.e. $N_{\mathrm{m}, \mathrm{H}_{2}} \simeq r_{\mathrm{a}, \mathrm{H}_{2}} \gg r_{\mathrm{d}, \mathrm{H}_{2}}$. In that case, the hydrogen surface coverage is to be derived from the measured flux (by solving Eq. (10)) and taken out of Eq. (35) (combining $r_{\mathrm{a}, \mathrm{H}}$ (25) and $r_{\mathrm{d}, \mathrm{H}}$ (32) to $\left.\theta_{\mathrm{H}}=(1-\theta)\left(b_{\mathrm{H}_{2}} p_{\mathrm{H}_{2}}\right)^{\left(1 / n_{\mathrm{H}_{2}}\right)}\right)$ :

$$
\theta_{i}=\frac{\left(b_{i} p_{i}\right)^{1 / n_{i}}}{1+\frac{\theta_{\mathrm{H}}}{1-\theta}+\sum_{i \neq \mathrm{H}_{2}}\left(b_{i} p_{i}\right)^{1 / n_{i}}} \text { for } i \neq \mathrm{H}_{2}
$$

\subsubsection{Hydrogen absorption in metallic palladium}

In solution equilibrium of hydrogen atoms in palladium, the chemical potential of the hydrogen gas in the $\alpha$-phase

$\mu_{\mathrm{H}_{2}}=\mu_{\mathrm{H}_{2}}^{0}+R T \ln \left(p_{\mathrm{H}_{2}}\right)$

equals the chemical potential of hydrogen atoms dissolved in a palladium matrix [62]

$\mu_{\mathrm{H}}=\mu_{\mathrm{H}}^{0}+R T \ln \left(\frac{x_{\mathrm{H}}}{x_{\mathrm{Pd}}-x_{\mathrm{H}}}\right)+\Delta \mu_{\mathrm{H}}$

where stoichiometry dictates $\mu_{\mathrm{H}}=\frac{1}{2} \mu_{\mathrm{H}_{2}}$. The term $\Delta \mu_{\mathrm{H}}$ accounts for deviations from ideal solution. Ideally, $\Delta \mu_{\mathrm{H}}=0$ and the isotherm reduces to Sieverts' law:

$\sqrt{p_{\mathrm{H}_{2}}}=\exp \left(\frac{\mu_{\mathrm{H}}^{0}-\frac{1}{2} \mu_{\mathrm{H}_{2}}^{0}}{R T}\right) \frac{x_{\mathrm{H}}}{\chi_{\mathrm{Pd}}-x_{\mathrm{H}}}$

More generally applicable isotherms have been presented in the literature, accounting for $\Delta \mu_{\mathrm{H}}$ as a function of the conditions in the system (specifically, temperature and hydrogen partial pressure), as reviewed by Manchester et al. [9]. In the relevant range of conditions for palladium membranes, however, the absorption isotherm for hydrogen can often also be successfully approximated by a simplified equation 
$c_{\mathrm{H}}=K_{0} \exp \left(\frac{E_{\mathrm{k}}}{R T}\right) p_{\mathrm{H}_{2}}^{n}$

with $0.5 \leq n \leq 1$, again depending on temperature and hydrogen partial pressure $[10,36,63,64]$. It should be noted that in case bulk diffusion of hydrogen atoms is the rate limiting step in permeation, the value of $n$ is not necessarily equal to 0.5 [3], because the shape of the hydrogen absorption isotherm at higher hydrogen partial pressures leads to $n>0.5[36,64]$.

\section{Results and discussion}

\subsection{Membrane stability}

The results from membrane stability measurements in pure hydrogen are shown in Fig. 5. There is a slight increase in hydrogen permeance of the membrane and the permeance is linearly corrected for this small increase over time, using hydrogen/nitrogen experiments as an extra reference point at $637 \mathrm{~h}$ before the carbon monoxide/hydrogen/nitrogen measurements.

\subsection{Pure hydrogen permeation}

The measured flux in pure hydrogen permeation tests was used to determine the intrinsic flux equation for the metallic palladium layer. The driving force was corrected for the pressure drop in the membrane support, following the procedure in [10]. Nonlinear regression was used to determine the parameters in the flux equation (22) as summarised in Table 3. The quality of fit is well within the $\pm 10 \%$ range for the major part of the measurements as shown in Fig. 6. A larger deviation is observed for the smallest fluxes, which is likely due to the larger relative contribution of measurement errors. The fitted value of $n$ is 0.66 , which is comparable to the value found in a previous study [10] and literature [65]. The apparent activation energy for permeation, which is in fact a product of the activation energy for diffusion and the energy of solution as argued in Section 2.2.4, is found to be $8 \pm 3 \mathrm{~kJ} \mathrm{~mol}^{-1}$, which is consistent with measurements of Hysep palladium membranes over the years at our laboratories. It is on the lower end yet within the range reported in the literature, both in experimental and theoretical studies, of $7-29 \mathrm{~kJ} \mathrm{~mol}^{-1}[16,28,63,66-$ 71]. It is intrinsically difficult to accurately determine the activation energy because it is mathematically confounded with the preexponential term $Q_{0}$.

The regressed flux equation parameters can be factorised into contributions by the adsorption isotherm and bulk diffusion, as derived above (Eq. (24)). Note that no surface limitations are expected based on the kinetic relations developed in Section 2.2.3. The activation energy for the permeance $\left(E_{\mathrm{a}}, 8 \mathrm{~kJ} \mathrm{~mol}^{-1}\right)$ is the

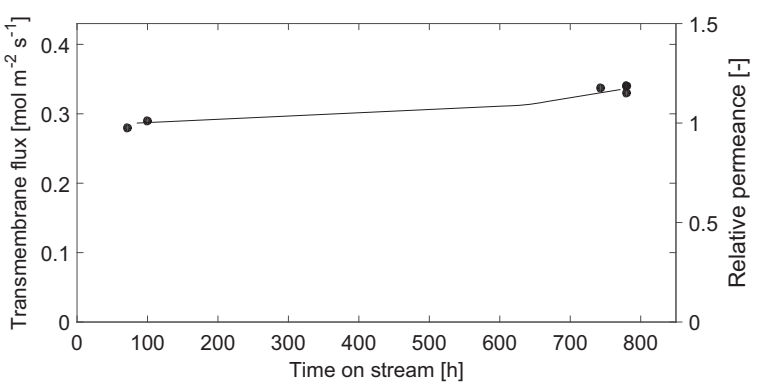

Fig. 5. Hydrogen transmembrane flux (markers) in repeated pure hydrogen reference measurements at $400{ }^{\circ} \mathrm{C}, p_{\mathrm{H}_{2}, \mathrm{r}}=2.1 \mathrm{bar}, p_{\mathrm{H}_{2}, \mathrm{p}}=1.1 \mathrm{bar}$ and permeance correction (line); syngas measurements were performed between 257 and $722 \mathrm{~h}$ on stream, $\mathrm{H}_{2} / \mathrm{CO} / \mathrm{N}_{2}$ measurements starting at $662 \mathrm{~h}$ on stream, the point at $637 \mathrm{~h}$ estimated from $\mathrm{H}_{2} / \mathrm{N}_{2}$ measurements.
Table 3

Regressed membrane flux equation (22) parameters.

\begin{tabular}{lllll}
\hline Parameter & Estimate & \multicolumn{2}{l}{ Estimated error } & Unit \\
\hline$Q_{0}$ & $1.43 \cdot 10^{-3}$ & \pm & $0.79 \cdot 10^{-3}$ & $\mathrm{~mol} \mathrm{~m}^{-2} \mathrm{~s}^{-1} \mathrm{~Pa}^{-0.66}$ \\
$E_{\mathrm{a}}$ & 8.0 & \pm & 2.9 & $\mathrm{~kJ} \mathrm{~mol}^{-1}$ \\
$\mathrm{n}$ & 0.66 & \pm & 0.04 & \\
\hline
\end{tabular}

Error estimate with 95\% confidence interval.

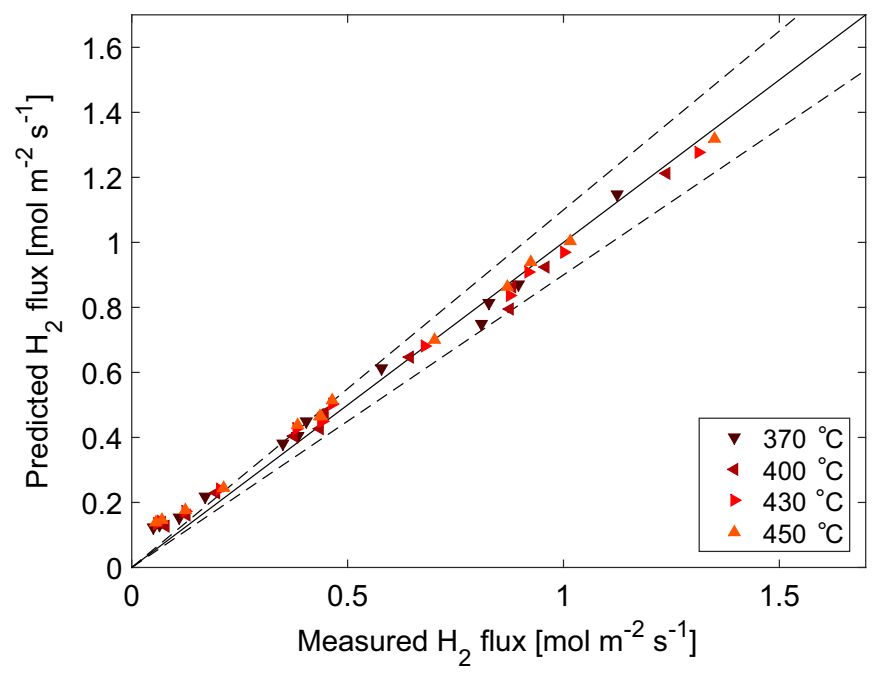

Fig. 6. Parity plot of the predicted versus measured hydrogen flux for pure hydrogen conditions.

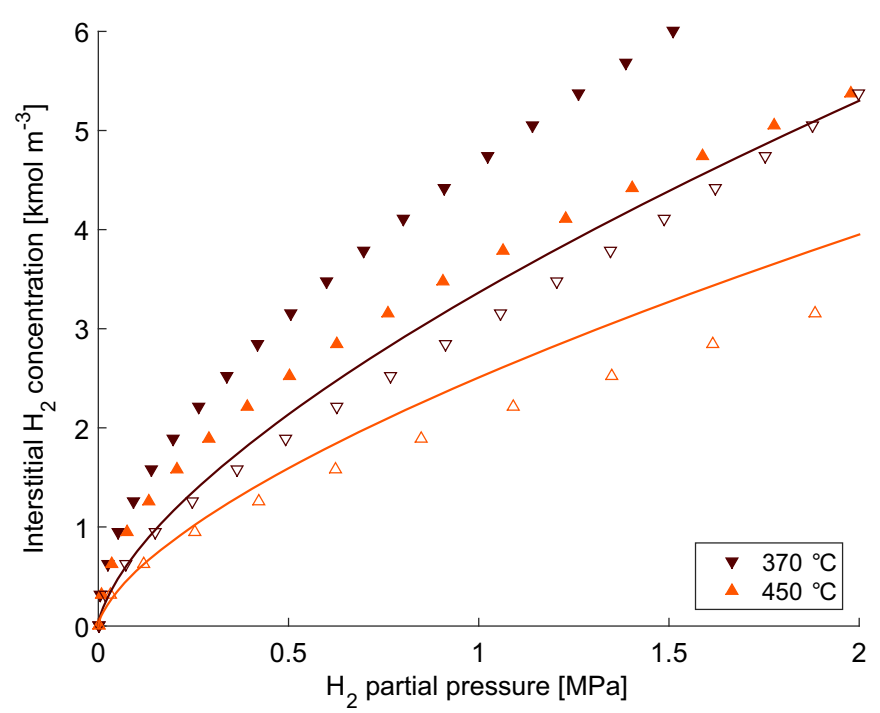

Fig. 7. Derived isotherm (lines, Eq. (42)) compared to literature data at $370{ }^{\circ} \mathrm{C}$ (brown) and $450{ }^{\circ} \mathrm{C}$ (orange); closed symbols Manchester et al. [9], open symbols Deveau et al. [28]. (For interpretation of the references to colour in this figure caption, the reader is referred to the web version of this paper.)

difference between the activation energy for diffusion $\left(E_{D}\right.$, $\left.22.2 \mathrm{~kJ} \mathrm{~mol}^{-1}[37]\right)$ and the absorption energy $\left(E_{\mathrm{k}}\right)$, so in the current range of conditions ( $370-450{ }^{\circ} \mathrm{C}, 1-30$ bar hydrogen) the absorption isotherm of hydrogen is approximated by

$c_{\mathrm{H}}=0.0275 \exp \left(\frac{14.2 \cdot 10^{3}}{R T}\right) p_{\mathrm{H}_{2}}^{0.66}$ 


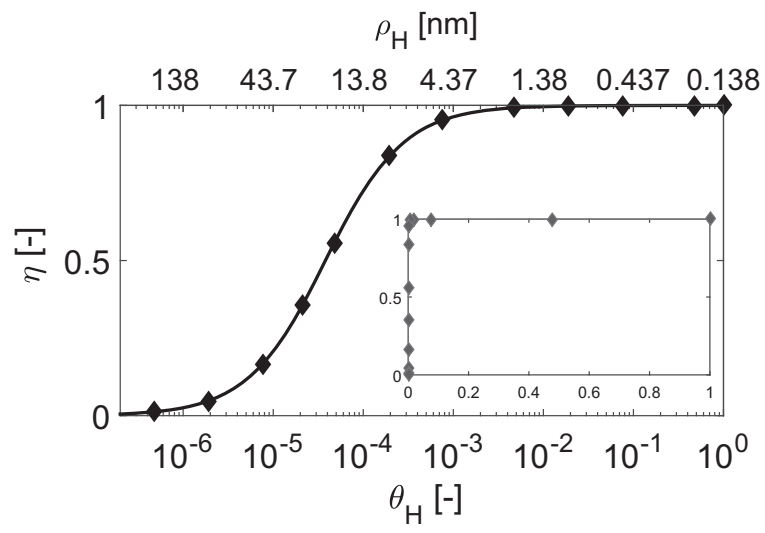

Fig. 8. Simulation results (markers) and regressed model (Eq. (43), line) for the relative hydrogen flux $(\eta)$ versus available sites for hydrogen $\left(\theta_{\mathrm{H}}\right)$ predicted with the cylindrical diffusion model for constriction resistance on logarithmic scale, inset shows the same on a linear scale.

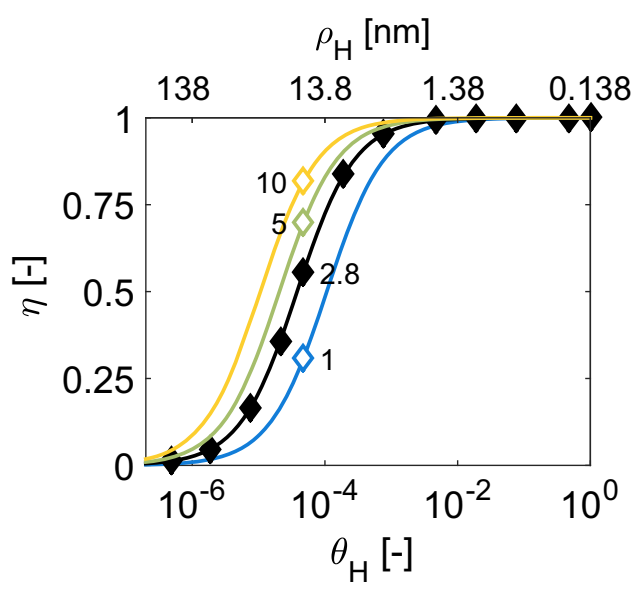

Fig. 9. Simulation results (markers) and regressed model (Eq. (43), line) for the relative hydrogen flux $(\eta)$ versus available sites for hydrogen $\left(\theta_{\mathrm{H}}\right)$ for membrane thickness of $1,2.8,5$, and $10 \mu \mathrm{m}$.

While the adsorption isotherm is thus derived in an indirect manner (and literature data in this specific range of conditions is scarce) it compares reasonably well with both the isotherm by Manchester et al. [9] and the more recent isotherm by Deveau et al. [28], as shown in Fig. 7.

\subsection{Hydrogen permeation with inhibition}

The actual flux relative to the flux without inhibition, $\eta$, which shows a decline due to a reduced surface coverage by adsorbed hydrogen atoms is shown in Fig. 8. Without inhibition, the surface coverage by adsorbed hydrogen atoms is close to one, the value of $\rho_{\mathrm{H}}$ approaches $0.138 \mathrm{~nm}$, and the value of $\eta$ is one. With inhibition, the surface coverage by hydrogen decreases and $\rho_{\mathrm{H}}$ increases but for $\theta_{\mathrm{H}} \geq 10^{-3}$ the reduced surface coverage is compensated for by lateral diffusion in the palladium membrane and the flux is not significantly affected. For $\theta_{\mathrm{H}}<10^{-3}, \rho_{\mathrm{H}}>4 \mathrm{~nm}$, there is a pronounced decline in flux. The value of $\eta$ as a function of $\theta_{\mathrm{H}}$ could be fitted by a phenomenological equation

$\eta=\left(\frac{1}{\alpha \theta_{\mathrm{H}}}+\frac{\alpha-\theta_{\mathrm{H}}}{\alpha}\right)^{-1}$

with $\alpha=26,275 \pm 190$ at 95\% confidence level, shown in Fig. 8 . This parameter is specific for the current membrane having a thickness of $2.8 \mu \mathrm{m}$, but not affected by concentration (hydrogen partial pressures) or temperature. The constriction resistance

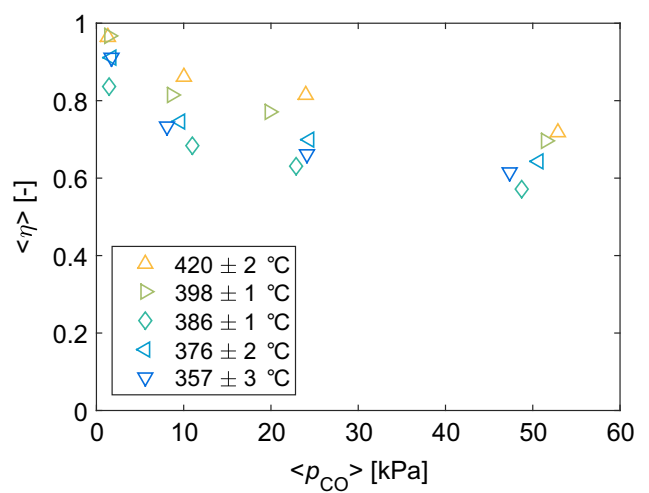

Fig. 10. Measured value of $\eta$ for $\mathrm{CO} / \mathrm{H}_{2} / \mathrm{N}_{2}$ feed gas mixtures, partial pressure calculated as the average between inlet (feed conditions) and outlet (permeate measurement); 22 bar feed pressure, 2 bar permeate pressure, $y_{\mathrm{CO}, \mathrm{f}}=0.001-0.02$, $y_{\mathrm{H}_{2}, \mathrm{f}}=0.6, y_{\mathrm{N}_{2}, \mathrm{f}}=0.38-0.4$.

simulations have been repeated for $\delta_{\mathrm{m}}=1 \mu \mathrm{m}$ and $\delta_{\mathrm{m}}=10 \mu \mathrm{m}$, see Fig. 9. The value of $\alpha$ decreases with increasing membrane thickness. Clearly, thicker membranes have a lower transmembrane flux for a given driving force and also a larger relative contribution of lateral diffusion of hydrogen atoms in the membrane. The constriction resistance model will lead to an already significant inhibition at lower surface coverage for thinner membranes than for thicker membranes. Consequently, the susceptibility of a membrane to inhibition is anticipated to be inversely proportional to its thickness.

In fact, results of repeated simulations of hydrogen diffusion across the palladium membrane for varying thickness for $\rho_{\mathrm{H}}=20 \mathrm{~nm}$ are shown in Fig. 9. Clearly shown are the increasing impact of lateral diffusion and the correspondingly reduced impact of inhibition with increasing membrane thickness. For the most severe inhibitive conditions (low temperature, high carbon monoxide partial pressure) in the current set, no increase in membrane flux is expected from hypothetically reducing the palladium thickness below $1 \mu \mathrm{m}$.

The value of $\langle\eta\rangle$ established from the single inhibition component experiments (either carbon monoxide, carbon dioxide, or steam added to hydrogen/nitrogen feed) are shown in Figs. 10-12, respectively. Clear inhibition effects are present for all species. For carbon monoxide, the effect is already significant below $10 \mathrm{kPa}$. For higher temperatures of $398-420^{\circ} \mathrm{C}$, the inhibition effect by carbon monoxide becomes less with increasing temperature. For temperatures below $400{ }^{\circ} \mathrm{C}$, the effect of temperature is unclear. Measurements with carbon dioxide in the feed also show a reduction in the apparent permeance. As shown in Fig. 11, there is no significant inhibition at $420^{\circ} \mathrm{C}$ but an increasing effect for decreasing temperatures. The effect is significantly smaller for carbon dioxide than for carbon monoxide. In fact, the observed inhibition by carbon dioxide is attributed to the carbon monoxide formed in the separator module, see Fig. 11, right. The inhibition effect of steam was somewhat less pronounced than for the carbon oxides, but clearly presents at all temperatures.

Based on the flux balance (Eq. (34)), and the kinetics of hydrogen adsorption and desorption, $\theta_{\mathrm{CO}}$ and $\theta_{\mathrm{H}_{2} \mathrm{O}}$ can be estimated. Two representative examples will be discussed first, highlighting the complex relation between surface coverage and inhibition on one hand, and the observed decline in flux on the other. In the first, $61 \mathrm{vol} \%$ hydrogen in nitrogen was fed to the membrane, yielding a hydrogen transmembrane flux of $1.05 \mathrm{~mol} \mathrm{~m}^{-2} \mathrm{~s}^{-1}$. The average feed side hydrogen concentration was $47 \mathrm{vol} \%$. Using Eqs. (27) and (33), it was found that the rates of adsorption and desorption of molecular hydrogen were both $84 \mathrm{~mol} \mathrm{~m}^{-2} \mathrm{~s}^{-1}$ and, 

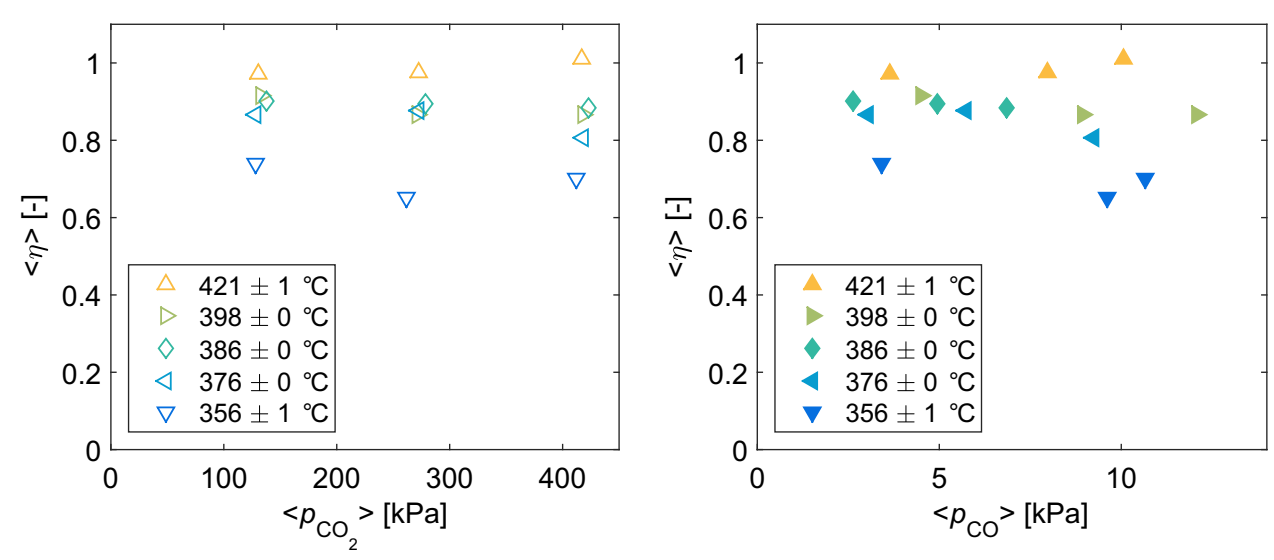

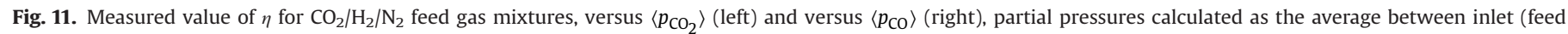
conditions) and outlet (permeate measurement); 22 bar feed pressure, 2 bar permeate pressure, $y_{\mathrm{CO}_{2}, \mathrm{f}}=0.05-0.15, y_{\mathrm{H}_{2}, \mathrm{f}}=0.6, y_{\mathrm{N}_{2}, \mathrm{f}}=0.25-0.35$.

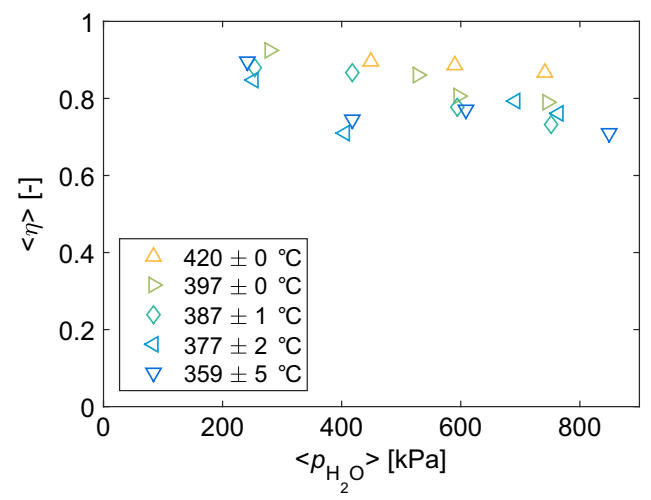

Fig. 12. Measured value of $\eta$ for $\mathrm{H}_{2} \mathrm{O} / \mathrm{H}_{2} / \mathrm{N}_{2}$ feed gas mixtures, partial pressure calculated as the average between inlet (feed conditions) and outlet (permeate measurement); 22 bar feed pressure, 2 bar permeate pressure, $y_{\mathrm{H}_{2} \mathrm{O}, \mathrm{f}}=0.1-0.29$, $y_{\mathrm{H}_{2}, \mathrm{f}}=0.6, y_{\mathrm{N}_{2}, \mathrm{f}}=0.14-0.3$.

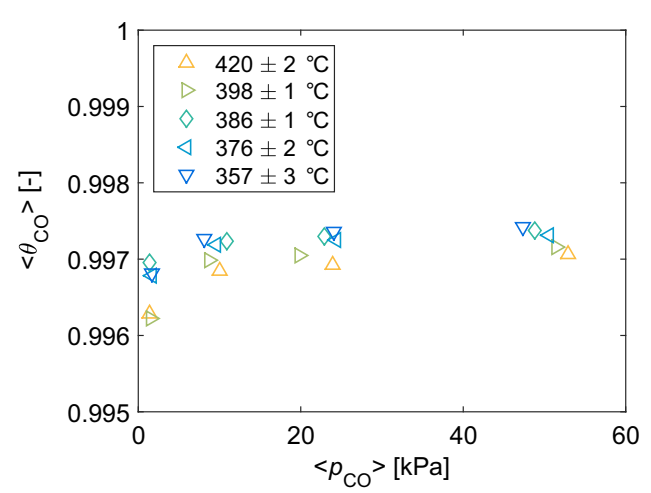

Fig. 13. Estimated value of $\theta_{\mathrm{CO}}$ for $\mathrm{CO} / \mathrm{H}_{2} / \mathrm{N}_{2}$ feed gas mixtures; 22 bar feed pressure, 2 bar permeate pressure, $y_{\mathrm{CO}, \mathrm{f}}=0.001-0.02, y_{\mathrm{H}_{2}, \mathrm{f}}=0.6, y_{\mathrm{N}_{2}, \mathrm{f}}=0.38-0.4$.

correspondingly, $\theta_{\mathrm{H}}=0.993$. The second example was measured using a feed of $60 \mathrm{~mol} \%$ hydrogen and $2 \mathrm{~mol} \%$ carbon monoxide in nitrogen. The transmembrane flux was $0.83 \mathrm{~mol} \mathrm{~m}^{-2} \mathrm{~s}^{-1}$ and the average hydrogen concentration $48 \mathrm{vol} \%$. The intrinsic flux in the absence of inhibition would have been $0.97 \mathrm{~mol} \mathrm{~m}^{-2} \mathrm{~s}^{-1}$, which makes $\eta=0.62$. Using Eq. (43) and the measured flux, $\theta_{\mathrm{H}}=6 \cdot 10^{-5}$. From Eq. (32), the rate of hydrogen desorption (on the retentate side) is $10^{-7}$, the fraction of unoccupied sites is $3 \cdot 10^{-3}$, and consequently $\theta_{\mathrm{CO}}=0.997$. Clearly, due to the lateral diffusion of hydrogen atoms in the metal, i.e. the constriction resistance, the decrease in hydrogen coverage does not cause a commensurate

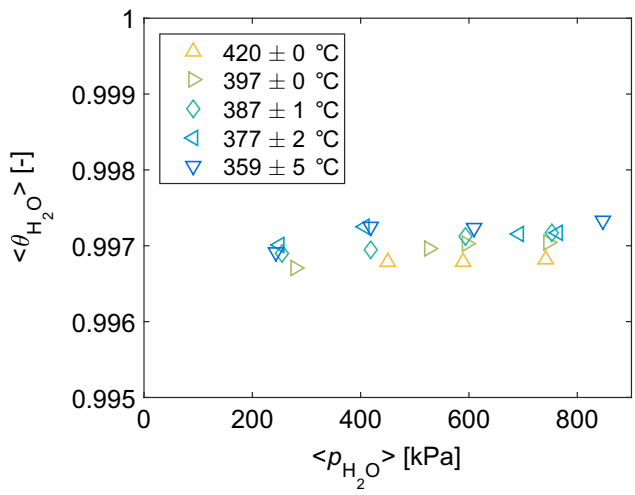

Fig. 14. Estimated value of $\theta_{\mathrm{H}_{2} \mathrm{O}}$ for $\mathrm{H}_{2} \mathrm{O} / \mathrm{H}_{2} / \mathrm{N}_{2}$ feed gas mixtures; 22 bar feed pressure, 2 bar permeate pressure, $y_{\mathrm{H}_{2} \mathrm{O}, \mathrm{f}}=0.1-0.29, y_{\mathrm{H}_{2}, \mathrm{f}}=0.6, y_{\mathrm{N}_{2}, \mathrm{f}}=0.14-0.3$.

Table 4

Regressed interaction parameters with $95 \%$ confidence interval for $\mathrm{CO}$ and $\mathrm{H}_{2} \mathrm{O}$.

\begin{tabular}{lc}
\hline$b_{\mathrm{CO}}\left(\mathrm{kPa}^{-1}\right)$ & $b_{\mathrm{H}_{2} \mathrm{O}}\left(\mathrm{Pa}^{-1}\right)$ \\
\hline $194 \pm 103$ & $100 \pm 19$ \\
\hline
\end{tabular}

Table 5

Regressed flux reduction coefficients with 95\% confidence interval for $\mathrm{CO}$ and $\mathrm{H}_{2} \mathrm{O}$.

\begin{tabular}{lll}
\hline Temperature $\left({ }^{\circ} \mathrm{C}\right)$ & $K_{\mathrm{CO}}\left(\mathrm{MPa}^{-1}\right)$ & $K_{\mathrm{H}_{2} \mathrm{O}}\left(\mathrm{MPa}^{-1}\right)$ \\
\hline 357 & $11.6 \pm 5.6$ & $0.39 \pm 0.26$ \\
377 & $6.2 \pm 2.2$ & $0.27 \pm 0.10$ \\
386 & $7.5 \pm 3.4$ & $0.23 \pm 0.17$ \\
397 & $5.0 \pm 1.6$ & $0.18 \pm 0.08$ \\
420 & $5.6 \pm 1.6$ & $0.17 \pm 0.08$ \\
\hline
\end{tabular}

decrease in flux.

The estimates for $\theta_{\mathrm{CO}}$ and $\theta_{\mathrm{H}_{2} \mathrm{O}}$ are shown in Figs. 13 and 14. Unfortunately, the high values of $\theta_{i}$ and small difference do not allow for a meaningful fit of the adsorption isotherm equations for the entire dataset. From the single inhibitive species measurements shown in Figs. 13 and 14, the values for $b_{\mathrm{CO}}$ and $b_{\mathrm{H}_{2} \mathrm{O}}$ could be estimated using Eq. (37) according to the values reported in Table 4 . The regression has been repeated with $n_{\mathrm{H}_{2} \mathrm{O}}=1$, but the quality of the dataset is not sufficient to discriminate. No significant parameter estimates could be made from the dataset with all syngas constituents. Complementary study of the surface of palladium under inhibition by in situ techniques such as Fourier transform infrared spectroscopy (FTIR) and X-ray photoelectron 


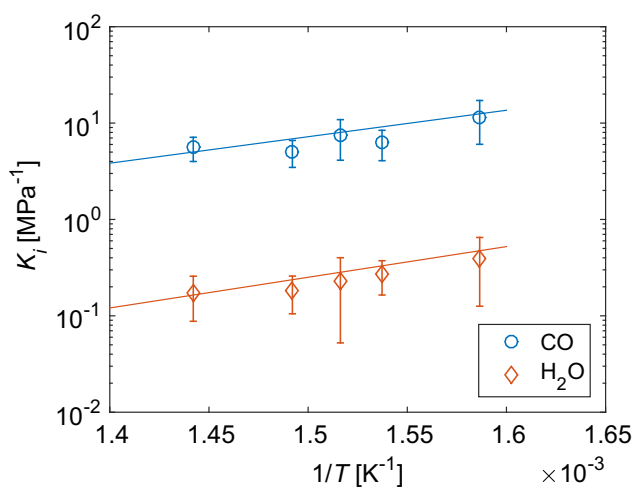

Fig. 15. Arrhenius plot of $K_{i}$ versus inverse temperature for $\mathrm{CO}$ and $\mathrm{H}_{2} \mathrm{O}$ (Table 5).

spectroscopy (XPS) might enable to quantify the competitive adsorption equilibrium. Instead, the reduction in flux, $\langle\eta\rangle$, versus partial pressure of carbon monoxide, carbon dioxide, and steam has been fitted by a linear regression model for each of the five temperature levels. This is an interaction model rather than adsorption isotherm, because $\theta_{i}$ versus $p_{i}$ could not be fitted accurately as discussed below. Hence no adsorption isotherm equation (e.g., Langmuir) is fitted but a general linear regression model instead:

$\langle\eta\rangle=1-K_{\mathrm{CO}}\left\langle p_{\mathrm{CO}}\right\rangle-K_{\mathrm{CO}_{2}}\left\langle p_{\mathrm{CO}_{2}}\right\rangle-K_{\mathrm{H}_{2} \mathrm{O}}\left\langle p_{\mathrm{H}_{2} \mathrm{O}}\right\rangle$

All data, including full syngas mixtures, were used to regress the parameters. The interaction parameter for carbon dioxide proved to be statistically insignificant at the $95 \%$ confidence level and was removed from the model $\left(K_{\mathrm{CO}_{2}}=0\right)$. The effect of carbon dioxide may be better correlated by the corresponding concentration of carbon monoxide, see Fig. 11. For carbon monoxide and steam, significant interaction parameters were found at each of the five temperature levels, shown in Table 5.

An Arrhenius plot of the flux reduction coefficients is shown in Fig. 15. The temperature dependence of the coefficients corresponds to an apparent activation energies of $E_{\mathrm{CO}}=42 \mathrm{~kJ} \mathrm{~mol}^{-1}$, and $E_{\mathrm{H}_{2} \mathrm{O}}=49 \mathrm{~kJ} \mathrm{~mol}^{-1}$, even though the relation between partial pressures and $\eta$ is not to be interpreted directly in terms of an adsorption isotherm.

When comparing the inhibition effect in the current study with the literature, two aspects appear to be of crucial importance. First is the hydrogen partial pressure in the system. It readily follows from the system of equations for adsorption kinetics derived above that a higher partial pressure of hydrogen leads to a higher value for $\theta_{\mathrm{H}}$, and consequently a lower value for the surface coverage by inhibiting species in general. Additionally, at higher $\theta_{\mathrm{H}}$, the equilibrium reactions (Table 2, A and B) lead to a lower concentration of surface adsorbed oxygen atoms. The effect of $p_{\mathrm{H}_{2}}$ was reported by Israni and Harold [23] already and its impact will be further discussed below. The second important aspect of the system is to properly account for the relation between the thickness of a membrane and the observed inhibition effect, i.e. the contribution of the surface and the bulk. The impact that a certain degree of surface site blocking has on the transmembrane flux is a function of the thickness of the membrane. The constriction resistance model derived in Section 2.2.2 aims to quantify this relationship by accounting not only for the one-dimensional diffusion of hydrogen from the retentate to the permeate side of the metallic membrane, but also for transverse diffusion. Due to the constriction resistance effect, thicker membranes (having a lower intrinsic permeance) will exhibit a larger contribution by transverse diffusion and consequently less inhibition for a given degree of surface site blocking. Conversely, many papers in the literature have interpreted $\langle\eta\rangle$ as being a direct measure of $\theta_{i}$, which would indeed

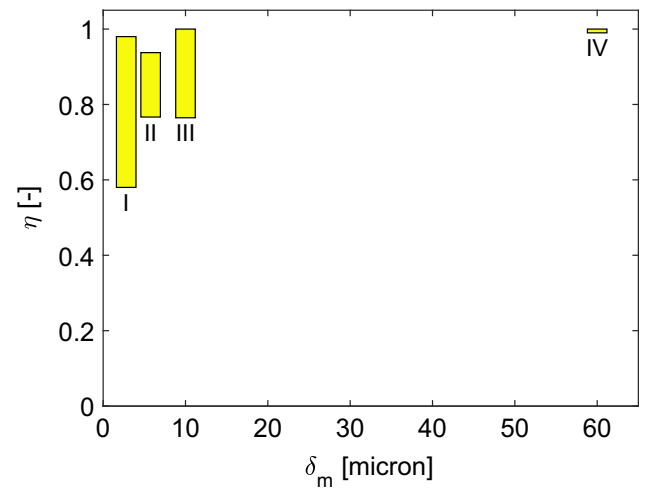

Fig. 16. Values of $\eta$ versus $\delta_{\mathrm{m}}$ for inhibition of palladium membranes by carbon monoxide at $350{ }^{\circ} \mathrm{C}$ and up: (I) this work $357-420^{\circ} \mathrm{C}$, (II) Li et al. [14] $400{ }^{\circ} \mathrm{C}$, (III) Li et al. [11] $380^{\circ} \mathrm{C}$, and (IV) Gallucci et al. [53] $350{ }^{\circ} \mathrm{C}$.

allow us to fit an adsorption isotherm, e.g. Langmuir equation, directly from the measured decline in flux. The constriction resistance model has indicated that there is a more complex relation between $\langle\eta\rangle$ and $\theta_{i}$ and consequently in this work no adsorption isotherm has been fitted.

As expected from the analysis above, experimental studies that were performed with thicker membranes have found less strong inhibition, as illustrated for inhibition by carbon monoxide for palladium membranes in Fig. 16. Gallucci et al. [53] measured inhibition for a $60 \mu \mathrm{m}$ palladium membrane in the range of 250 $450{ }^{\circ} \mathrm{C}$ and found no effect for carbon dioxide, and inhibition for up to $245 \mathrm{kPa}$ carbon monoxide at $250^{\circ} \mathrm{C}$ but not for $350^{\circ} \mathrm{C}$ and up. For a $60 \mu \mathrm{m}$ thick palladium-silver membrane at $374^{\circ} \mathrm{C}$, Barbieri et al. [21] measured significant inhibition by up to $300 \mathrm{kPa}$ carbon monoxide and successfully fitted a Sieverts-Langmuir equation with a fairly small carbon monoxide adsorption coefficient of $0.023 \mathrm{kPa}^{-1}$. Li et al. [11] measured a $10 \mu \mathrm{m}$ palladium membrane at $380^{\circ} \mathrm{C}$ and found no inhibition by carbon monoxide below approximately $12 \mathrm{kPa}$ partial pressure, also weaker than present results suggest. These differences with the current data are well explained by the difference in membrane thickness, in combination with the constriction resistance model.

With thinner membranes, the results in the literature are consistent with the results from this study, provided that the partial pressure of hydrogen is taken into account. The current set of measurements has been performed at hydrogen partial pressures of 11-15 bar. Mejdell et al. [54] measured a $3 \mu \mathrm{m}$ palladiumsilver membrane with $p_{\mathrm{H}_{2}}=2.7 \mathrm{bar}$ and found significantly stronger inhibition by up to $15 \mathrm{kPa}$ carbon monoxide at $350{ }^{\circ} \mathrm{C}$. At $300^{\circ} \mathrm{C}$, Israni and Harold [23] found inhibition by carbon monoxide, carbon dioxide, and steam for a $3.9 \mu \mathrm{m}$ thick palladiumsilver membrane at 5 bar total pressure. For up to $60 \mathrm{kPa}$ carbon monoxide, $\langle\eta\rangle$ decreased to 0.4 , which is again significantly stronger than in the current data at $350{ }^{\circ} \mathrm{C}$ and up. Steam caused less inhibition than carbon monoxide and for up to $90 \mathrm{kPa}$ steam, $\langle\eta\rangle$ decreased to 0.8 . This is again significantly more pronounced than in the current study. More importantly, the relative inhibition effect of carbon monoxide and steam is consistent, which indicates that the inhibition mechanisms are identical. Li et al. [11] measured at hydrogen partial pressures of up to 3 bar and found that for the addition of 5-15 $\mathrm{kPa}$ steam, $\langle\eta\rangle$ remained fairly constant at $83-70 \%$ which appears to be a stronger effect than observed in the current study (Fig. 12). Similarly, Hou and Hughes [12] used a 5$6 \mu \mathrm{m}$ thick palladium-silver membrane at $275^{\circ} \mathrm{C}$ and $p_{\mathrm{H}_{2}}=2$ bar and found stronger inhibition by up to $15 \mathrm{kPa}$ steam than by the same concentration of carbon monoxide. Indeed, for much higher $p_{\mathrm{H}_{2}}$ of $25 \mathrm{bar}$, Li et al. [14] found no inhibition by $600 \mathrm{kPa}$ steam at $400{ }^{\circ} \mathrm{C}$. 
The current study found no significant inhibition effect for carbon dioxide in the range of $350-420^{\circ} \mathrm{C}$, except for the inhibition that is caused by carbon monoxide that is produced in the module. This is in line with observations by Hou and Hughes [12], who found no effect for carbon dioxide at $325^{\circ} \mathrm{C}$ and up. In contrast, Israni and Harold [23] did find a significant inhibition effect by carbon dioxide, but this was observed below $300{ }^{\circ} \mathrm{C}$. Consequently, carbon dioxide does not appear to inhibit hydrogen permeation in the temperature range of $350-420{ }^{\circ} \mathrm{C}$.

The constriction resistance model proved to be an important element in the analysis of the inhibition measurements. In the derivation of the model (Eq. (14)) a homogeneous palladium surface is assumed, where each exposed palladium atom represents a single adsorption site. The permeation model is based on a description of the metal surface in terms of the average surface coverage by hydrogen atoms, and the average distance between two adsorbed hydrogen atoms. The surface of the membrane, in contrast, is made up of various crystallographic planes, kinks and terraces. For hydrogen, however, this is of little consequence as Behm et al. [72] have shown that the adsorption energy of hydrogen on palladium is hardly affected by the crystallographic orientation of the surface. Adsorbed carbon monoxide may form ordered adlayers on a palladium surface that are dependent on the nanostructure of the surface [43]. Gao et al. [48] and Gallucci et al. [53] have shown stable minima for carbon monoxide on palladium sites, but also a small difference in adsorption energy for hollow and bridge positions which will allow carbon monoxide to block several hydrogen adsorption sites. Further refinement of the constriction resistance model may account for surface heterogeneity and provide a better insight in the relation between surface coverage by inhibitive species and the decrease in hydrogen flux.

The constriction resistance model is based on the assumption that adsorption is localised. Alternatively, the surface adsorption could be described as a dynamic equilibrium, in which adsorbed species can move over the surface. The surface coverage is then a surface and time average of local and dynamic adsorption equilibrium, $\left\langle\left\langle\theta_{\mathrm{H}}\right\rangle\right\rangle$. A recent example of this line of reasoning can be found in the work of Abir and Sheintuch [24]. Based on first principles calculations and a dynamic adsorption equilibrium, they predict larger hydrogen surface coverage (down to $\left\langle\left\langle\theta_{\mathrm{H}}\right\rangle\right\rangle \approx 0.2$ ) in case of inhibition. Remarkably, this approach reverts to Langmuir and extended Langmuir isotherms for the surface coverage by hydrogen and inhibiting species, which in fact are derived from the assumption of localised adsorption [73]. Nonetheless, with the higher hydrogen surface coverage there is no transition in rate limiting step which is in contrast with the present findings based on the localised model. In order to further investigate the differences between the two approaches, the experimental data have been reinterpreted in terms of the surface average model. In such a

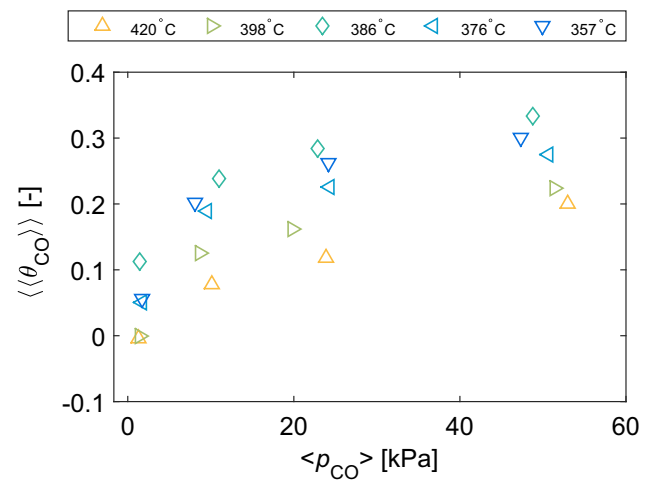

Fig. 17. Estimated value of $\left\langle\left\langle\theta_{\mathrm{CO}}\right\rangle\right\rangle$ for $\mathrm{CO} / \mathrm{H}_{2} / \mathrm{N}_{2}$ feed gas mixtures with the alternative surface average model (Eq. (45)); conditions as in Fig. 13.

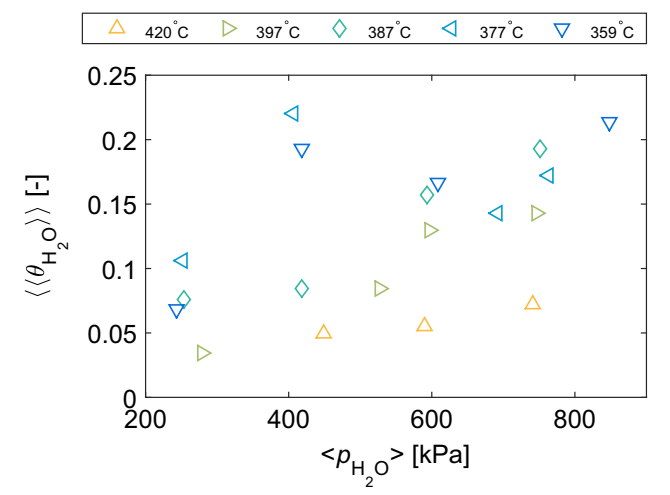

Fig. 18. Estimated value of $\left\langle\left\langle\theta_{\mathrm{H}_{2} \mathrm{O}}\right\rangle\right\rangle$ for $\mathrm{H}_{2} \mathrm{O} / \mathrm{H}_{2} / \mathrm{N}_{2}$ feed gas mixtures with the alternative surface average model (Eq. (45)); conditions as in Fig. 14.

case, the constriction resistance relation (Eq. (43)) does not apply. Instead,

$N_{\mathrm{H}}=-Q\left(\left\langle\left\langle\theta_{H}\right\rangle\right\rangle p_{\mathrm{H}_{2}, \mathrm{r}}^{n}-p_{\mathrm{H}_{2}, \mathrm{p}}^{n}\right)$

$\eta=\frac{\left\langle\left\langle\theta_{\mathrm{H}}\right\rangle\right\rangle p_{\mathrm{H}_{2, \mathrm{r}}}^{n}-p_{\mathrm{H}_{2, \mathrm{p}}}^{n}}{p_{\mathrm{H}_{2, \mathrm{r}}}^{n}-p_{\mathrm{H}_{2, \mathrm{p}}}^{n}}$

Reinterpretation of the observed decline in flux in terms of Eq. (46) leads to predicted values of $\left\langle\left\langle\theta_{H}\right\rangle\right\rangle$ in the range of $0.65-1$. The corresponding average surface coverage by inhibiting species carbon monoxide and steam are in the range of $0-0.3$, and $0.05-$ 0.2 , respectively (Figs. 17 and 18). Thus, the surface average model predicts lower coverage by inhibiting species, and no effect of membrane thickness. In this context, it is interesting to note that experimental evidence appears to indicate a thickness dependence of the inhibition phenomenon. This is indicated in Fig. 16. It is in line with model predictions using the constriction resistance model as discussed above and in contrast with the surface average model. Further study of the extent of hydrogen coverage in case of inhibition, e.g. by surface techniques discussed above or by systematic study of the susceptibility to inhibition as a function of membrane thickness, would clearly be of great scientific interest.

As discussed, two important conditions largely determine the extent of the inhibition effect besides the partial pressures of inhibiting species: the partial pressure of hydrogen and the thickness of the membrane. With respect to the first, it is crucial to measure the inhibition effect at gas phase conditions that resemble the envisaged industrial conditions. The current set of inhibition measurements at high hydrogen partial pressures are therefore an important addition to existing literature data. The findings with respect to the thickness of the membrane have implications for the development and production of palladium membranes. Over the last decades, ever thinner membranes have been produced that exhibited ever higher fluxes. In syngas, however, the inhibition effect will become more severe for thinner membranes and may partly offset the gain in intrinsic permeance.

\section{Conclusions}

A model has been developed for hydrogen permeation across palladium membranes in industrially relevant conditions, including the presence of inhibiting species. Model equations have been derived to describe the response of hydrogen adsorption and permeation to surface coverage by inhibiting species. The decline in flux due to a reduced surface coverage by adsorbed hydrogen 
atoms could be fitted by a phenomenological equation, based on the theory of constriction resistance.

Based on the derived kinetics of adsorption and desorption, $\theta_{\mathrm{CO}}$ and $\theta_{\mathrm{H}_{2} \mathrm{O}}$ have been estimated. Due to the high values of $\theta_{i}$ no full adsorption isotherm could be fitted for the entire dataset. Instead, the reduction in flux, $\langle\eta\rangle$, versus partial pressure of carbon monoxide, carbon dioxide, and steam has been fitted by a linear regression model. Significant interaction parameters were found at each of the five temperature levels for carbon monoxide and steam. The current study found no significant inhibition effect for carbon dioxide in the range of $350-420^{\circ} \mathrm{C}$, except for the inhibition that is caused by carbon monoxide that is produced from carbon dioxide by reverse water-gas shift in the module.

Besides the partial pressures of inhibiting species, two main aspects determine the inhibition effect: the partial pressure of hydrogen and the thickness of the membrane. It has been shown that it is crucial to measure the inhibition effect at gas phase conditions that resemble the envisaged industrial conditions. The constriction resistance model predicts that the susceptibility of a membrane to inhibition is inversely correlated to its thickness. Depending on the operating conditions, membranes have an optimal minimum thickness below which an increased intrinsic permeance is offset by an increased impact of inhibition.

\section{Acknowledgement}

Part of this research has been carried out in the context of the CATO-2 programme. CATO-2 is the Dutch national research programme on $\mathrm{CO}_{2}$ Capture and Storage technology (CCS). The programme is financially supported by the Dutch Government (Ministry of Economic Affairs) and the Industrial CATO-2 Consortium Parties. The authors gratefully acknowledge J.F. van Wees of ECN for performing the experiments and Dr. W.G. Haije of ECN, Dr. Fausto Gallucci of TU/e, and Ir. Peter Veenstra and Prof. Dr. Arian Nijmeijer of consortium partner Shell Global Solutions, Amsterdam (NL) for fruitful discussions.

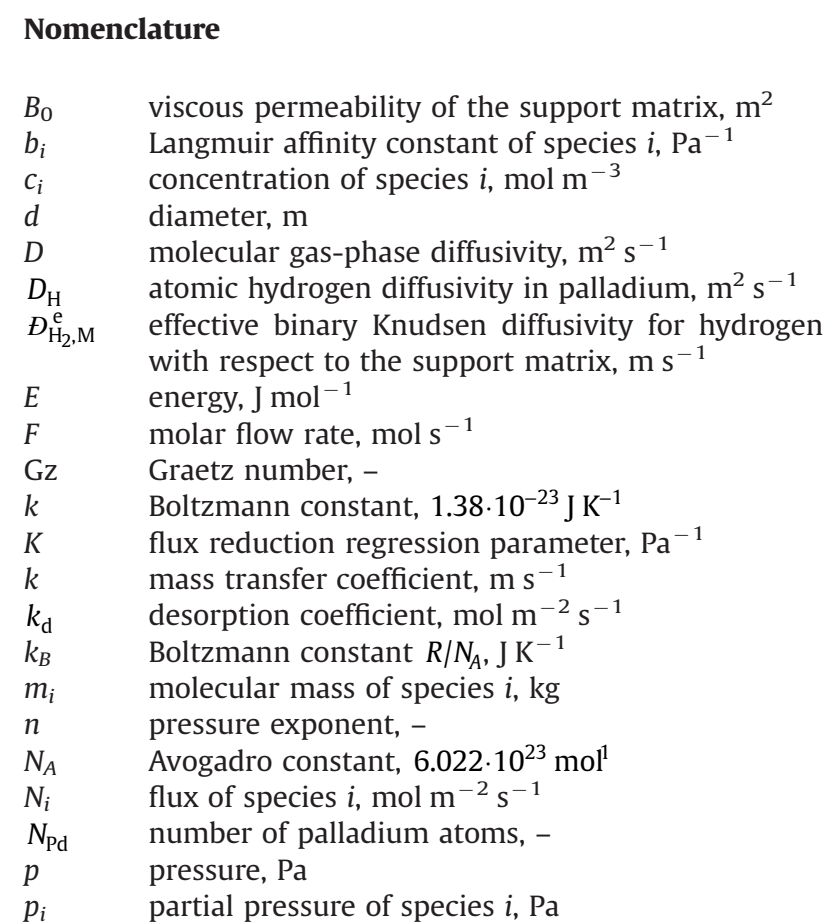

permeance, $\mathrm{mol} \mathrm{m}{ }^{-2} \mathrm{~s}^{-1} \mathrm{~Pa}^{-n}$ gas constant, $8.3145 \mathrm{~J} \mathrm{~mol}^{-1} \mathrm{~K}^{-1}$ radial coordinate, $\mathrm{m}$ radius of adsorption site, $0.14 \mathrm{~nm}$ rate of species $i, \mathrm{~mol} \mathrm{~m}^{-2} \mathrm{~s}^{-1}$ Reynolds number, -

Schmidt number, -

Sherwood number, -

sticking coefficient, -

initial sticking coefficient, at $\theta=0$, sticking coefficient of species $i$, temperature, $\mathrm{K}$ pairwise interaction energy, J mole fraction of species $i$ in the solid phase, mole fraction of species $i$ in the gas phase, axial coordinate, $\mathrm{m}$

Greek $\eta$

$\theta$

$\theta_{00}$

$\theta_{i}$

$\mu$

$\mu_{i}$

$\rho_{\mathrm{H}}$

Subscript

0 pre-exponential

a activation, adsorption diffusion desorption feed hydraulic absorption membrane outer retentate

\section{References}

[1] S.N. Paglieri, J.D. Way, Innovations in palladium membrane research, Sep. Purif. Rev. 31 (2002) 1-169.

[2] A. Basile, F. Gallucci, S. Tosti, Synthesis, characterization and applications of palladium membranes, Membr. Sci. Technol. 13 (2008) 255-323.

[3] S. Yun, S.T. Oyama, Correlations in palladium membranes for hydrogen separation: a review, J. Membr. Sci. 375 (2011) 28-45.

[4] F. Gallucci, E. Fernandez, P. Corengia, M. van Sint Annaland, Recent advances on membranes and membrane reactors for hydrogen production, Chem. Eng. Sci. 92 (2013) 40-66.

[5] N.W. Ockwig, T.M. Nenoff, Membranes for hydrogen separation, Chem. Rev. 107 (2007) 4078-4110.

[6] M. Gazzani, D.M. Turi, G. Manzolini, Techno-economic assessment of hydrogen selective membranes for $\mathrm{CO}_{2}$ capture in integrated gasification combined cycle, Int. J. Greenhouse Gas Control 20 (2014) 293-309.

[7] A. Goldbach, F. Bao, C. Qi, C. Bao, L. Zhao, C. Hao, C. Jiang, H. Xu, Evaluation of Pd composite membrane for pre-combustion $\mathrm{CO}_{2}$ capture, Int. J. Greenhouse Gas Control 33 (2015) 69-76.

[8] J. Boon, J.A.Z. Pieterse, J.W. Dijkstra, Y.C. van Delft, P. Veenstra, A. Nijmeijer, 
D. Jansen, Benchmarking of hydrogen selective membranes: experimental and modelling approach to compare membrane performance, Energy Procedia 37 (2013) 1020-1029.

[9] F.D. Manchester, A. San-Martin, J.M. Pitre, The H-Pd (hydrogen-palladium) system, J. Phase Equilibria 15 (1994) 62-83.

[10] J. Boon, J.A.Z. Pieterse, J.W. Dijkstra, M. van Sint Annaland, Modelling and systematic experimental investigation of mass transfer in supported palladium-based membrane separators, Int. J. Greenhouse Gas Control 11 (2012) S122-S129.

[11] A. Li, W. Liang, R. Hughes, The effect of carbon monoxide and steam on the hydrogen permeability of a Pd/stainless steel membrane, J. Membr. Sci. 165 (2000) 135-141.

[12] K. Hou, R. Hughes, The effect of external mass transfer, competitive adsorption and coking on hydrogen permeation through thin Pd/Ag membranes, J. Membr. Sci. 206 (2002) 119-130.

[13] F.C. Gielens, R.J.J. Knibbeler, P.F.J. Duysinx, H.D. Tong, M.A.G. Vorstman, J.T. F. Keurentjes, Influence of steam and carbon dioxide on the hydrogen flux through thin Pd/Ag and Pd membranes, J. Membr. Sci. 279 (2006) 176-185.

[14] H. Li, J. Dijkstra, J. Pieterse, J. Boon, R. Van den Brink, D. Jansen, Towards fullscale demonstration of hydrogen-selective membranes for $\mathrm{CO}_{2}$ capture: inhibition effect of WGS-components on the $\mathrm{H}_{2}$ permeation through three $\mathrm{Pd}$ membranes of $44 \mathrm{~cm}$ long, J. Membr. Sci. 363 (2010) 204-211.

[15] J. Catalano, M. Giacinti Baschetti, G.C. Sarti, Hydrogen permeation in palladium-based membranes in the presence of carbon monoxide, J. Membr. Sci. 362 (2010) 221-233.

[16] A.S. Augustine, Y.H. Ma, N.K. Kazantzis, High pressure palladium membrane reactor for the high temperature water-gas shift reaction, Int. J. Hydrog. Energy 36 (2011) 5350-5360.

[17] J. Catalano, M. Giacinti Baschetti, G.C. Sarti, Influence of water vapor on hydrogen permeation through $2.5 \mu \mathrm{m}$ Pd-Ag membranes, Int. J. Hydrog. Energy 36 (2011) 8658-8673.

[18] F. van Berkel, C. Hao, C. Bao, C. Jiang, H. Xu, J. Morud, T. Peters, E. Soutif, J. W. Dijkstra, D. Jansen, B. Song, Pd-membranes on their way towards application for $\mathrm{CO}_{2}$-capture, Energy Procedia 37 (2013) 1076-1084.

[19] J.M. Sánchez, M.M. Barreiro, M. Maroño, Bench-scale study of separation of hydrogen from gasification gases using a palladium-based membrane reactor Fuel 116 (2014) 894-903.

[20] M. Patrascu, M. Sheintuch, On-site pure hydrogen production by methane steam reforming in high flux membrane reactor: experimental validation, model predictions and membrane inhibition, Chem. Eng. J. 262 (2015) $862-874$.

[21] G. Barbieri, F. Scura, F. Lentini, G. De Luca, E. Drioli, A novel model equation for the permeation of hydrogen in mixture with carbon monoxide through $\mathrm{Pd}-\mathrm{Ag}$ membranes, Sep. Purif. Technol. 61 (2008) 217-224.

[22] A.L. Mejdell, M. Jøndahl, T.A. Peters, R. Bredesen, H.J. Venvik, Effects of CO and $\mathrm{CO}_{2}$ on hydrogen permeation through a $\sim 3 \mu \mathrm{m}$ Pd/Ag 23 wt.\% membrane employed in a microchannel membrane configuration, Sep. Purif. Technol. 68 (2009) 178-184.

[23] S.H. Israni, M.P. Harold, Methanol steam reforming in Pd-Ag membrane reactors: effects of reaction system species on transmembrane hydrogen flux, Ind. Eng. Chem. Res. 49 (2010) 10242-10250.

[24] H. Abir, M. Sheintuch, Modeling $\mathrm{H}_{2}$ transport through a Pd or Pd/Ag membrane, and its inhibition by co-adsorbates, from first principles, J. Membr. Sci. 466 (2014) 58-69.

[25] T.A. Peters, M. Stange, H. Klette, R. Bredesen, High pressure performance of thin Pd-23\% Ag stainless steel composite membranes in water gas shift gas mixtures; influence of dilution, mass transfer and surface effects on the hydrogen flux, J. Membr. Sci. 316 (2008) 119-127.

[26] J. Boon, H. Li, J.W. Dijkstra, J.A.Z. Pieterse, 2-dimensional membrane separator modelling: mass transfer by convection and diffusion, Energy Procedia 4 (2011) 699-706.

[27] T.L. Ward, T. Dao, Model of hydrogen permeation behavior in palladium membranes, J. Membr. Sci. 153 (1999) 211-231.

[28] N.D. Deveau, Y.H. Ma, R. Datta, Beyond Sieverts' law: a comprehensive microkinetic model of hydrogen permeation in dense metal membranes, J. Membr. Sci. 437 (2013) 298-311.

[29] R. de Vos (Ed.), Linking the Chain, Integrated CATO2 Knowledge Prepares for the Next Step in $\mathrm{CO}_{2}$ Capture \& Storage, CATO2, Utrecht, 2014.

[30] D. Jansen, J.W. Dijkstra, R.W. Van den Brink, T.A. Peters, M. Stange, R. Bredesen, A. Goldbach, H.Y. Xu, A. Gottschalk, A. Doukelis, Hydrogen membrane reactors for $\mathrm{CO}_{2}$ capture, Energy Procedia 1 (2009) 253-260.

[31] H. Li, J. Dijkstra, J. Pieterse, J. Boon, R. van den Brink, D. Jansen, WGS-mixture separation and WGS reaction test in a bench-scale multi-tubular membrane reactor, Energy Procedia 4 (2011) 666-673.

[32] Hysep, Hydrogen Separation Modules, 〈http://www.hysep.com/〉, 2014 (Accessed 21 October).

[33] R. Taylor, R. Krishna, Multicomponent Mass Transfer, vol. 2, John Wiley \& Sons, New York, 1993.

[34] J. Catalano, M.G. Baschetti, G.C. Sarti, Influence of the gas phase resistance on hydrogen flux through thin palladium-silver membranes, J. Membr. Sci. 339 (2009) 57-67.

[35] O. Nekhamkina, M. Sheintuch, Effective approximations for concentrationpolarization in Pd-membrane separators, Chem. Eng. J. 260 (2015) 835-845.
[36] T.B. Flanagan, D. Wang, Exponents for the pressure dependence of hydrogen permeation through Pd and Pd-Ag alloy membranes, J. Phys. Chem. C 114 (2010) 14482-14488.

[37] J. Völkl, G. Alefeld, Diffusion of hydrogen in metals, in: Hydrogen in Metals I, 1978, pp. 321-348.

[38] W. M. Haynes (Ed.), CRC Handbook of Chemistry and Physics, 95th ed., CRC Press/Taylor and Francis, Boca Raton, FL, Internet version 2015.

[39] H.S. Carslaw, J.C. Jaeger, Conduction of Heat in Solids, Clarendon Press, Oxford, 1959.

[40] J.A. Greenwood, Constriction resistance and the real area of contact, Br. J. Appl. Phys. 17 (1966) 1621.

[41] H. Tannenberger, H. Siegert, The Behavior of Silver Cathodes in Solid Electrolyte Fuel Cells, American Chemical Society, Washington, DC, pp. 281-300.

[42] F.P.F. van Berkel, F.H. van Heuveln, J.P.P. Huijsmans, Characterization of solid oxide fuel cell electrodes by impedance spectroscopy and $I-V$ characteristics, Solid State Ionics 72 (1994) 240-247.

[43] J.M. Thomas, W.J. Thomas, J. Anderson, M. Boudart, Principles and Practice of Heterogeneous Catalysis, vol. 638, VCH, Weinheim, 1997.

[44] D.A. King, M.G. Wells, Reaction mechanism in chemisorption kinetics: nitrogen on the $\{100\}$ plane of tungsten, Proc. R. Soc. Lond. A. Math. Phys. Sci. 339 (1974) 245-269.

[45] Y. Xiao, W. Dong, Molecular dynamics simulation of a complex surface reaction: the effect of coverage on $\mathrm{H}_{2}$ dissociation on Pd(111), Phys. Rev. B 83 (2011) 125418.

[46] P.A. Thiel, T.E. Madey, The interaction of water with solid surfaces: fundamental aspects, Surf. Sci. Rep. 7 (1987) 211-385.

[47] J.M. Heras, G. Estiu, L. Viscido, The interaction of water with clean palladium films: a thermal desorption and work function study, Appl. Surf. Sci. 108 (1997) 455-464.

[48] H. Gao, Y.S. Lin, Y. Li, B. Zhang, Chemical stability and its improvement of palladium-based metallic membranes, Ind. Eng. Chem. Res. 43 (2004) 6920-6930.

[49] T. Engel, H. Kuipers, A molecular-beam investigation of the reaction $\mathrm{H}_{2}+\frac{1}{2} \mathrm{O}_{2} \rightarrow \mathrm{H}_{2} \mathrm{O}$ on Pd111, Surf. Sci. 90 (1979) 181-196.

[50] C. Nyberg, C. Tengstål, Vibrational excitations of hydrogen and oxygen on Pd (100), Surf. Sci. 126 (1983) 163-169.

[51] H. Conrad, G. Ertl, J. Koch, E.E. Latta, Adsorption of CO on Pd single crystal surfaces, Surf. Sci. 43 (1974) 462-480.

[52] O. Dulaurent, K. Chandes, C. Bouly, D. Bianchi, Heat of adsorption of carbon monoxide on a $\mathrm{Pd} / \mathrm{Al}_{2} \mathrm{O}_{3}$ solid using in situ infrared spectroscopy at high temperatures, J. Catal. 188 (1999) 237-251.

[53] F. Gallucci, F. Chiaravalloti, S. Tosti, E. Drioli, A. Basile, The effect of mixture gas on hydrogen permeation through a palladium membrane: experimental study and theoretical approach, Int. J. Hydrog. Energy 32 (2007) 1837-1845.

[54] A.L. Mejdell, D. Chen, T.A. Peters, R. Bredesen, H.J. Venvik, The effect of heat treatment in air on $\mathrm{CO}$ inhibition of a $3 \mu \mathrm{m} \mathrm{Pd}-\mathrm{Ag}$ (23 wt.\%) membrane, J. Membr. Sci. 350 (2010) 371-377.

[55] J.R. Rostrup-Nielsen, J.H. Bak Hansen, $\mathrm{CO}_{2}$-reforming of methane over transition metals, J. Catal. 144 (1993) 38-49.

[56] D.J. Pettigrew, D.L. Trimm, N.W. Cant, The effects of rare earth oxides on the reverse water-gas shift reaction on palladium/alumina, Catal. Lett. 28 (1994) 313-319.

[57] A. Erdöhelyi, J. Cserenyi, E. Papp, F. Solymosi, Catalytic reaction of methane with carbon dioxide over supported palladium, Appl. Catal. A: Gen. 108 (1994) 205-219.

[58] S.W. Lee, J.S. Park, C.B. Lee, D.W. Lee, H. Kim, H.W. Ra, S.H. Kim, S.K. Ryi, $\mathrm{H}_{2}$ recovery and $\mathrm{CO}_{2}$ capture after water-gas shift reactor using synthesis gas from coal gasification, Energy 66 (2014) 635-642.

[59] M.A. Vannice, R.L. Garten, Supported palladium catalysts for methanation, Ind. Eng. Chem. Prod. Res. Dev. 18 (1979) 186-191.

[60] W. Wang, J. Gong, Methanation of carbon dioxide: an overview, Front. Chem. Sci. Eng. 5 (2011) 2-10.

[61] C. Ratnasamy, J.P. Wagner, Water gas shift catalysis, Catal. Rev. 51 (2009) 325-440.

[62] E. Wicke, H. Brodowsky, H. Züchner, Hydrogen in Metals II, Springer, Berlin (1978), p. 73-155.

[63] B.D. Morreale, M.V. Ciocco, R.M. Enick, B.I. Morsi, B.H. Howard, A.V. Cugini, K. S. Rothenberger, The permeability of hydrogen in bulk palladium at elevated temperatures and pressures, J. Membr. Sci. 212 (2003) 87-97.

[64] S. Hara, M. Ishitsuka, H. Suda, M. Mukaida, K. Haraya, Pressure-dependent hydrogen permeability extended for metal membranes not obeying the square-root law, J. Phys. Chem. B 113 (2009) 9795-9801.

[65] K.S. Rothenberger, A.V. Cugini, B.H. Howard, R.P. Killmeyer, M.V. Ciocco, B. D. Morreale, R.M. Enick, F. Bustamante, I.P. Mardilovich, Y.H. Ma, High pressure hydrogen permeance of porous stainless steel coated with a thin palladium film via electroless plating, J. Membr. Sci. 244 (2004) 55-68.

[66] J.P. Collins, J.D. Way, Preparation and characterization of a composite palladium-ceramic membrane, Ind. Eng. Chem. Res. 32 (1993) 3006-3013.

[67] V. Höllein, M. Thornton, P. Quicker, R. Dittmeyer, Preparation and characterization of palladium composite membranes for hydrogen removal in hydrocarbon dehydrogenation membrane reactors, Catal. Today 67 (2001) 33-42.

[68] D. Wang, J. Tong, H. Xu, Y. Matsumura, Preparation of palladium membrane over porous stainless steel tube modified with zirconium oxide, Catal. Today 
93-95 (1980) 689-693.

[69] W.H. Chen, P.C. Hsu, Hydrogen permeation measurements of Pd and Pd-Cu membranes using dynamic pressure difference method, Int. J. Hydrog. Energy 36 (2011) 9355-9366.

[70] B. Dittmar, A. Behrens, N. Schödel, M. Rüttinger, T. Franco, G. Straczewski, R. Dittmeyer, Methane steam reforming operation and thermal stability of new porous metal supported tubular palladium composite membranes, Int. J. Hydrog. Energy 38 (2013) 8759-8771.
[71] G. Straczewski, J. Völler-Blumenroth, H. Beyer, P. Pfeifer, M. Steffen, I. Felden, A. Heinzel, M. Wessling, R. Dittmeyer, Development of thin palladium membranes supported on large porous 310L tubes for a steam reformer operated with gas-to-liquid fuel, Chem. Eng. Process.: Process Intensif. 81 (2014) 13-23.

[72] R.J. Behm, K. Christmann, G. Ertl, Adsorption of hydrogen on Pd(100), Surf. Sci. 99 (1980) 320-340.

[73] I. Langmuir, The adsorption of gases on plane surfaces of glass, mica and platinum, J. Am. Chem. Soc. 40 (1918) 1361-1403. 